\title{
A Summary of Health Hazard Evaluations: Issues Related to Occupational Exposure to Isocyanates, 1989 to 2002
}




\section{ORDERING INFORMATION}

Individual Health Hazard Evaluations (HHEs) presented in this document may be requested by referencing the Hazard Evaluations and Technical Assistance (HETA) number listed. To receive these documents or other information about occupational safety and health topics, contact the National Institute for Occupational Safety and Health (NIOSH) at

NIOSH Publications Dissemination

4676 Columbia Parkway

Cincinnati, OH 45226-1998

Telephone: 1-800-35-NIOSH (1-800-356-4674)

Fax: 1-513-533-8573

E-mail: pubstaft@cdc.gov

or visit the NIOSH Web site at www.cdc.gov/niosh

This document is in the public domain and may be freely copied or reprinted. Mention of any company or product does not constitute endorsement by NIOSH.

DHHS (NIOSH) Publication No. 2004 116 
The Health Hazard Evaluations and Technical Assistance (HETA) Program responds to requests from employers, employees, employee representatives, and other Federal, State, and local agencies. Through a staff of industrial hygienists, engineers, occupational physicians, epidemiologists, other health professionals, and support personnel, the Hazard Evaluations and Technical Assistance Branch (HETAB) collaborates with appropriate personnel in other divisions of the National Institute for Occupational Safety and Health (NIOSH) to respond to approximately 450 requests for assistance each year. The typical HETA response to a request for assistance results in (l) an evaluation of whether chemical, physical, biological, or other agents are hazardous as used or found in the workplace and (2) the development of recommendations for control procedures, improved work practices, and medical programs to reduce exposure levels and prevent adverse health effects. Health Hazard Evaluation (HHE) site visits are conducted if warranted, and interim and final reports are developed and distributed to employees, unions, management, and relevant Federal and State agencies. When the HETA request is from a Federal, State, or local agency for assistance in investigating another workplace, NIOSH provides only the technical assistance (TA) requested and does not conduct a complete HHE. The results of individual evaluations may trigger wider studies of similar exposures in other settings or may stimulate recommendations for implementation or modification of health standards. Approximately 12,000 evaluations have been completed since the inception of the HETA Program in 1972.

Requests received by the HETA Program tend to reflect emerging occupational problems, such as isocyanate exposure and other priority areas. Forty-six isocyanate-related site visits were conducted from 1989 to 2002. The HHE requests came from a variety of sources-including manufacturers of plastic, wood, and automotive products, coal mines, schools, and offices. Sixteen of the requests were made by management, eleven by union, eleven by three or more employees, six by government, and two by management and employees jointly. This document first presents some background information about isocyanate exposures, health effects, analytical methods, and general recommendations that are provided for most isocyanate-related HHEs. The analytical methods section is important because of the complexities and limitations associated with measuring isocyanate exposures. (More detailed information can be gained from the NIOSH Manual of Analytical Methods.) The major portion of this document presents the titles and summaries of the site visits related to isocyantes conducted between 1989 and 2002. In most cases multiple exposures were investigated at the work site; sometimes isocyanate exposures were a primary issue and sometimes not. In many cases, corrective measures were made in response to the evaluation and recommendations made by NIOSH investigators.

The purpose of this HHE summary document is to amass the past 14 years of isocyanate-related HHEs in a concise format for easy reference and examination by NIOSH researchers, customers, and partners. Any individual report or letter of interest can easily be requested. The scope and presentation of the individual HHEs vary based on the requesters' needs and the project officers' professional judgment. The document is not meant to be a state-of-the-art review, but instead, it is intended to provide general insight into the types of isocyanate HHE requests received, and HETAB's response to them.

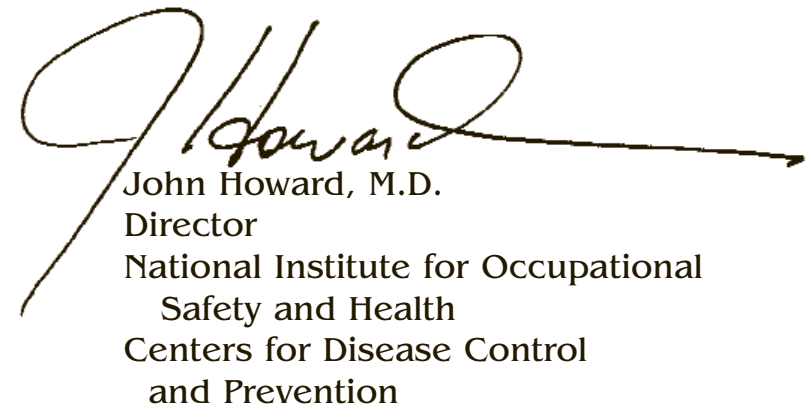




\section{CONURIBUTORS}

Prepared by

Beth Donovan Reh, M.H.S.

\section{Editor}

Jane Weber, M.Ed.

\section{Design/Desktop Publisher \\ Donna Pfirman}

NIOSH Printing Office

Penelope Arthur

Web Production

David Wall

Donna Pfirman

\section{Project Officers for Individual Health} Hazard Evaluations

Emily Allen, M.P.H.

Dan Almaguer, M.S.

Bruce P. Bernard, M.D., M.P.H.

Mary E. Brown, D.V.M., M.P.H.

Gina Bueno, M.D.

Joseph E. Burkhart, C.I.H.

Nancy Clark Burton, M.P.H., M.S., C.I.H.

John A. Decker, M.S.

Alan Echt, M.P.H., C.I.H.

Thomas Hales, M.D.

Bruce W. Hills, M.S., C.I.H.

Edward J. Hoekstra, M.D., M.S.

Bradley Husberg, R.N., M.S.P.H.

Elizabeth Jennison, M.D., M.P.H.

Max Kiefer, M.S., C.I.H.

Stuart Kiken, M.D.

Elizabeth Knutti, R.N., B.S.N.

Greg Kullman, Ph.D., C.I.H.

Ali Lopez, M.D.

Robert Malkin, D.D.S., Dr. P.H.

Dino Mattorano

Charles S. McCammon, Ph.D.

Mary Newman, Ph.D.

David L. Orgel, M.D., M.P.H.

Chris Piacitelli, I.H.

Christopher M. Reh, M.S.

Stanley Salisbury, C.I.H.

Bambi Sorensen

Robert Streicher, Ph.D.

Doug Trout, M.D., M.H.S.

Randy L. Tubbs, Ph.D.

Corrado Ugolini, M.D., M.P.H.

\section{ABBREVIATIONS}

Isocyanate

HDI 1,6-hexamethylene diisocyanate hexamethylene-1,6-diisocyanate 1,6-diisocyanate 1,6-diisocyanatohexane hexamethylene diisocyanate

HDI BT Hexamethylendiisocyanate-biurettrimer

HMDI Methylene bis (4-cyclohexylisocyanate)

HMTA Hexamethylenetetramine

IPDI Isophorone diisocyanate

MAP 1-(9-anthracenylmethyl)piperazine

MDA 4,4' methylenedianiline Methylenedianaline

MDI 4,4'-diphenylmethane diisocyanate Methyl diphenyl diisocyanate Methelene bisphenyl isocyanate Diphenylmethane diisocyanate Methylene diphenyl diisocyanate Methylene diphenyl isocyanate

NDI 1,5-naphthalene diisocyanate

PPI 2,6-diisopropylphenyl isocyanate

TDA Toluene diamine

TDI 2,4- and/or 2,6-toluene diisocyanate Trioxide toluene diisocyanate Toluene diisocyanate Toluene iisocyanate

TRIG Total reactive isocyanate group

Other

ACGIH American Conference of Governmental Industrial Hygienists

AHU Air handling unit

${ }^{\circ} \mathrm{C}$ Degrees Celsius

CA Carcinogen

CFR Code of Federal Regulations

$\mathrm{CI}$ Confidence interval

$\mathrm{CL} \quad$ Ceiling limit, an exposure that shall not be exceeded during any part of the workday

$\mathrm{cm}^{2} \quad$ Square centimeters

DOP Dioctyl phthalate

ELISA Enzyme-linked immunosorbent assay

${ }^{\circ} \mathrm{F} \quad$ Degrees Fahrenheit

FEV Forced expiratory volume in one second

FVC Forced vital capacity

GA General area (air sample) 
HETA Hazard Evaluations and Technical Assistance

HETAB Hazard Evaluations and Technical Assistance Branch

HHE Health Hazard Evaluation

HP Hypersensitivity pneumonitis

HPLC High pressure liquid chromatography

HVAC Heating, ventilating, and airconditioning

IAQ Indoor air quality

IARC International Agency for Research on Cancer

IEQ Indoor environmental quality

IgE Immunoglobulin E (antibody)

IgG Immunoglobulin G (antibody)

IH Industrial hygiene

LEV Local exhaust ventilation

LFC Lowest feasible concentration

LOD Limit of detection (analytical method)

LOQ Limit of quantitation (analytical method)

Lpm Liters per minute

MDC Minimum detectable concentration (the smallest amount of a material which can be reliably detected). The MDC is calculated by dividing the analytical LOD by a representative air volume.

MEK Methyl ethyl ketone

mg Milligram

$\mathrm{mg} / \mathrm{l} \quad$ Milligrams per liter

$\mathrm{mg} / \mathrm{m}^{3}$ Milligrams per cubic meter of air

MIBK Methyl ethyl isobutyl ketone

MIK Methyl isobutyle ketone

$\mathrm{mL} \quad$ Milliliter

mm Millimeter

MQC Minimum quantifiable concentration (the smallest amount of a material which can be reliably measured). The MQC is calculated by dividing the analytical LOQ by a representative air volume.
MSDS Material safety data sheet

NA Not applicable

ND Not detected

NDBA Nitosodibutylamine,

NDEA Nitosodiethylamine

NDMA Nitrosodimethylamine

NIOSH National Institute for

Safety and Health

nm Nanometer

NMOR Nitrosomorpholine

NPIP Nitrosopiperidine

OSHA Occupational Safety and Health

Administration

$P \quad$ Probability factor (statistical)

PBZ Personal breathing-zone air sample

PEL Permissible exposure limit (OSHA)

ppb Parts (of a contaminant) per billion parts of air

PPE Personal protective equipment

ppm Parts (of a contaminant) per million parts of air

PRR Prevalence rate ratio

QFF Quartz fiber filter

$R \quad$ Correlation factor (statistical)

REL Recommended exposure limit (NIOSH exposure criteria)

SIC Standard Industrial Classification

STEL Short-term exposure limit

TA Technical assistance

TLV Threshold limit value (ACGIH exposure criteria)

TWA Time-weighted average

UK-HSE United Kingdom's Health and Safety Executive

VOC Volatile organic compounds

ug Microgram

$\mu \mathrm{g} / \mathrm{m}^{3} \quad$ Micrograms of contaminant per cubic meter of air (a unit of concentration)

$\mu \mathrm{gNCO} / \mathrm{m}^{3}$ Micrograms of isocyanate groups per cubic meter of air 


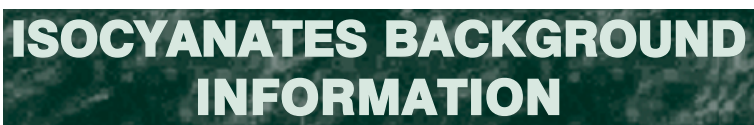

The unique feature common to all diisocyanates is that they consist of two $\mathrm{N}=\mathrm{C}=\mathrm{O}$ (isocyanate) functional groups attached to an aromatic or aliphatic parent compound. Because of the highly unsaturated nature of the isocyanate functional group, the diisocyanates readily react with compounds containing active hydrogen atoms (electrophiles). Thus, the diisocyanates readily react with water (humidity), alcohols, amines, etc.; diisocyanates also react with themselves to form either dimers or trimers. When a diisocyanate species reacts with a primary, secondary, or tertiary alcohol, a carbamate (NHCOO-) group is formed, which is commonly referred to as a urethane. Reactions involving a diisocyanate species and a polyol result in the formation of cross-linked polymers; i.e., polyurethanes. Hence, they are used in surface coatings, polyurethane foams, adhesives, resins, elastomers, binders, and sealants. Many material safety data sheets (MSDSs) use isocyanate-related terms interchangeably. For the purpose of this report, terms are defined as follows.

Diisocyanates (Monomers): The difunctional isocyanate species from which polyisocyanates and polyurethanes are derived. Common examples of monomeric isocyanates include 1,6-hexamethylene diisocyanate (HDI), 2,4- and/or 2,6-toluene diisocyanate (TDI), 4,4' diphenylmethane diisocyanate (MDI), methylene bis (4-cyclohexylisocyanate) (HMDI), isophorone diisocyanate (IPDI), and 1,5-naphthalene diisocyanate (NDI). Commercial-grade TDI is an $80: 20$ or $65: 35$ mixture of the $2,4-$ and 2,6-isomers of TDI, respectively.

Polyisocyanates: Species possessing free isocyanate groups and derived from monomeric isocyanates either by directly linking these monomeric units (a homopolymer) or by reacting these monomers with di- or poly-functional alcohols or amines (a copolymer).
Prepolymers: Species possessing free isocyanate groups, prepared from the reaction of a polyol with an excess of di- or polyisocyanate. Commercially available isocyanate products frequently contain prepolymers in lieu of more volatile isocyanate monomers.

Oligomeric Isocyanates (Oligomers): Relatively low molecular weight polyisocyanates.

Intermediates: Species possessing free isocyanate groups, formed during use of an isocyanate product by partial reaction of the isocyanate species with a polyol.

In general, the types of exposures encountered during the use of isocyanates (i.e., monomers, prepolymers, polyisocyanates, and oligomers) in the workplace are related to the vapor pressures of the individual compounds. The lower molecular weight isocyanates tend to volatilize at room temperature, creating a vapor inhalation hazard. Conversely, the higher molecular weight isocyanates do not readily volatilize at ambient temperatures but are still an inhalation hazard if aerosolized or heated in the work environment. The latter is important since many reactions involving isocyanates are exothermic in nature, thus providing the heat for volatilization. As exposure limits decrease, the volatility of solid materials becomes an issue. To reduce the vapor hazards associated with the lower molecular weight diisocyanates, prepolymer and polyisocyanate forms of these diisocyanates were developed and have replaced the monomers in many product formulations. An example is the biuret of HDI, which consists of three molecules of HDI monomer joined together to form a higher molecular weight oligomer having similar characteristics to those found in the monomer. Also, many MDI product formulations consist of a combination of MDI monomer and a MDI-based polyisocyanate (such as polymethylene polyphenyl isocyanate). Many prepolymer and polyisocyanate formulations contain a small fraction (usually less than $1 \%$ ) of unreacted monomer. 
Isocyanates exist in many different physical forms in the workplace. Not only are workers potentially exposed to the unreacted monomer, prepolymer, polyisocyanate, and/or oligomer species found in a given product formulation, they can also be exposed to partially reacted isocyanatecontaining intermediates formed during polyurethane production. In addition, isocyanate containing mixtures of vapors and aerosols can be generated during the thermal degradation of polyurethane coatings and plastics. The capability to measure all isocyanate containing substances in air, whether they are in monomer, prepolymer, polyisocyanate, oligomer, and/or intermediate forms, is important when assessing a worker's total airborne isocyanate exposure.

\section{HEALTH EFFECTS}

Exposure to isocyanates is irritating to the skin, mucous membranes, eyes, and respiratory tract. ${ }^{1,2}$ The most common adverse health outcome associated with isocyanate exposure is asthma due to sensitization; less prevalent are contact dermatitis (both irritant and allergic forms) and hypersensitivity pneumonitis (HP). ${ }^{2,3,4}$ Contact dermatitis can result in symptoms such as rash, itching, hives, and swelling of the extremities. ${ }^{1,4}$ A worker suspected of having isocyanateinduced asthma/sensitization will exhibit the traditional symptoms of acute airway obstruction, e.g., coughing, wheezing, shortness of breath, tightness in the chest, and nocturnal awakening. ${ }^{1,3}$ An isocyanateexposed worker may first develop an asthmatic condition (i.e., become sensitized) after a single (acute) exposure, but sensitization usually takes a few months to several years of exposure. . $3,3,5,6,7^{\text {The asthmatic reac- }}$ tion may occur minutes after exposure (immediate), several hours after exposure (late), or a combination of both immediate and late components after exposure (dual)..$^{3,6}$ The late asthmatic reaction is the most common, occurring in approximately $40 \%$ of isocyanate sensitized workers. ${ }^{8}$ After sensitization, any exposure, even to levels below an occupational exposure limit or standard, can produce an asthmatic response that may be life threatening. Experience with isocyanates has shown that monomeric, prepolymeric and polyisocyanate species are capable of producing respiratory sensitization in exposed workers. ${ }^{9}$ 10,11,12,13,14,15,16,17,18,19,20,21,22,23,24,25 Since the intermediates may be chemically similar to these compounds, it is reasonable to assume that they may also produce this condition. Prevalence estimates for isocyanate-induced asthma in exposed worker populations vary considerably: from $5 \%$ to $10 \%$ in diisocyanate production facilities ${ }^{5,26}$ to $25 \%$ in polyurethane production plants ${ }^{26,27}$ and $30 \%$ in polyurethane seatcover operations. $^{28}$ The scientific literature contains a limited amount of animal data suggesting that dermal exposure to diisocyanates may produce respiratory sensitization. ${ }^{29,30,31,32}$ This finding has not been tested in dermally exposed workers.

HP also has been described in workers exposed to isocyanates. ${ }^{33,34,35,36}$ Currently, the prevalence of isocyanate-induced HP in the worker population is unknown and is considered to be rare when compared to the prevalence rates for isocyanate-induced asthma. ${ }^{4}$ Whereas asthma is an obstructive respiratory disease usually affecting the bronchi, HP is a restrictive respiratory disease affecting the lung parenchyma (bronchioles and alveoli). The initial symptoms associated with isocyanate-induced HP are flu-like, including shortness of breath, nonproductive cough, fever, chills, sweats, malaise, and nausea. ${ }^{3,4}$ After the onset of HP, prolonged and/or repeated exposures may lead to an irreversible decline in pulmonary function and lung compliance and to the development of diffuse interstitial fibrosis. ${ }^{3,4}$ Early diagnosis is difficult since many aspects of HP, i.e., the flu-like symptoms and the changes in pulmonary function, are manifestations common to many other respiratory diseases and conditions.

The only effective intervention for workers with isocyanate-induced sensitization (asthma) or HP is cessation of all isocyanate exposure. This can be accomplished by removing the worker from the work environment where 
isocyanate exposure occurs, or by providing the worker with supplied-air respiratory protection and preventing any dermal exposures.

\section{EXPOSURE GRTIERIA}

The primary sources of exposure criteria for workplace inhalation exposures in the United States follow: (1) the National Institute for Occupational Safety and Health (NIOSH) recommended exposure limits (RELs), ${ }^{37}$ (2) the American Conference of Governmental Industrial Hygienists (ACGIH) Threshold Limit Values (TLVs $\left.{ }^{\circledR}\right),{ }^{38}$ and (3) the U.S. Department of Labor, Occupational Safety and Health Administration (OSHA) permissible exposure limits (PELs). ${ }^{39}$ These include exposure criteria for diisocyanates. In July 1992, the 11th Circuit Court of Appeals vacated the 1989 OSHA PEL Air Contaminants Standard. OSHA is currently enforcing the 1971 standards, which are listed as transitional values in the current Code of Federal Regulations; however, some States operating their own OSHAapproved job safety and health programs can have lower limits. Table 1 contains a comparison of the respective NIOSH RELs, ACGIH TLVs, OSHA PELs, and United Kingdom's Health and Safety Executive (UK-HSE) exposure criteria for the isocyanates. The UK-HSE has taken a different approach, i.e., developing a nonspecific standard based on the total reactive isocyanate groups (TRIGs) in a volume of air..$^{40}$ (The TRIGs in air can be determined using data from NIOSH Method 5522.) First, the monomer and oligomer concentrations are summed to obtain the total weight of isocyanate-containing compounds in a given air sample. Next, the molecular weight of the isocyanate functional groups in the parent compound is divided by the molecular weight of the parent compound. This yields a constant that reflects the percentage of a compound's molecular weight that is contributed by the TRIGs. For MDI and MDI-based oligomers the TRIG's constant is 0.34; for TDI and TDI-based oligomers the TRIG's constant is 0.48 . Finally, the total weight of isocyanate-

Table 1: NIOSH, ACGIH, OSHA, and UK-HSE Exposure Criteria for Isocyanates

\begin{tabular}{|c|c|c|c|c|c|c|c|}
\hline \multirow[b]{2}{*}{$\begin{array}{c}\text { Isocyanate } \\
\text { Species }\end{array}$} & \multicolumn{3}{|c|}{$\begin{array}{c}\text { Exposure Criteria-Full-Shift } \\
\text { TWAs } \mu g / \mathrm{m}^{3}\end{array}$} & \multicolumn{4}{|c|}{$\begin{array}{c}\text { Exposure Criteria-Short Term or } \\
\text { Ceiling Limits } \mu \mathrm{g} / \mathrm{m}^{3}\end{array}$} \\
\hline & $\begin{array}{c}\text { NIOSH } \\
\text { REL }\end{array}$ & $\begin{array}{c}\text { ACGIH } \\
\text { TLV }\end{array}$ & UK-HSE & $\begin{array}{l}\text { NIOSH REL } \\
\text { Ceiling }\end{array}$ & $\begin{array}{c}\text { ACGIH } \\
\text { TLV- } \\
\text { STEL }\end{array}$ & $\begin{array}{l}\text { UK-HSE } \\
\text { Ceiling }\end{array}$ & $\begin{array}{c}\text { OSHA } \\
\text { PEL } \\
\text { Ceiling }\end{array}$ \\
\hline TDI & CA-LFC $^{*}$ & 36 & None & None & 140 & None & 140 \\
\hline MDI & 50 & 51 & None & 200 & None & None & 200 \\
\hline HDI & 35 & 34 & None & 140 & None & None & None \\
\hline HMDI & None & 54 & None & 210 & None & None & None \\
\hline IPDI & 45 & 45 & None & 180 & None & None & None \\
\hline NDI & 40 & None & None & 170 & None & None & None \\
\hline TRIG & None & None & 20 & None & None & 70 & None \\
\hline
\end{tabular}

* NIOSH considers TDI to be an occupational CA and recommends that exposures be reduced to the LFC.

Abbreviations: ACGIH=American Conference of Governmental Industrial Hygienists;

$\mathrm{CA}=$ carcinogen; $\mathrm{HDI}=1,6$-hexamethylene diisocyanate; $\mathrm{HMDI}=$ methylene bis (4-cyclohexylisocyanate); IPDI=Isophorone diisocyanate; LFC=lowest feasible concentration; MDI=Methyl diphenyl diisocyanate $\mathrm{NDI}=1,5$-naphthalene diisocyanate; NIOSH=National Institute for Occupational Safety and Health; OSHA=Occupational Safety and Health Administration; PEL=Permissible exposure limit (OSHA); REL=Recommended Exposure Limit; STEL=Short-term exposure limit; TDI=Toluene diisocyanate; TLV=Threshold Limit Value (ACGIH exposure criteria); TRIG=total reactive isocyanate group; TWA=Time-weighted average; UK-HSE=United Kingdom's Health and Safety Executive; $\mu \mathrm{g} / \mathrm{m}^{3}=$ Micrograms of contaminant per cubic meter of air (a unit of concentration). 
containing compounds in a given air sample is multiplied by the TRIGs constant, and the product is the concentration of TRIGs in air.)

The standards and limits listed in Table 1 are calculated on the basis of a general standard that isocyanate exposures should not exceed the vapor equivalent of an 8-hour time-weighted average (TWA) exposure of $5 \mathrm{ppb}$, or a short-term or ceiling exposure of $20 \mathrm{ppb}$. NIOSH recommends using this standard basis to calculate exposure limits for diisocyantes not specifically mentioned in the REL. The NIOSH REL is for TWA diisocyanate exposures up to 10-hours per workday, and the ACGIH TLV is an 8-hour TWA exposure. The NIOSH RELs ceiling limit (CL) and ACGIH shortterm exposure limits (STELs) are based on 10- and 15-minute TWA exposures, respectively, and should not be exceeded during the work shift. The OSHA CL is a concentration that should never be exceeded during a workday. OSHA does not have a full shift, TWA PEL for any of the diisocyanate species.

In recent years there has been an interest in isocyanate exposures associated with 2 component polyurethane paints, especially as related to the autobody industry. NIOSH has conducted a few HHEs in these workplaces and expects to do more in the future. The most common isocyanate-bearing substances found in these paints are polyisocyanates based on HDI. Two forms of HDI-based polyisocyanates exist: an aliphatic form, which is biuret of HDI, and a ringed compound, which is HDI trimer. Both are known to cause respiratory sensitization (occupational asthma), and dermal exposures are an issue. These paints also contain a very small residual amount of HDI (monomer). Currently, there are no NIOSH, OSHA, or ACGIH evaluation criteria for HDI-based polyisocyanates. In some past HHEs, NIOSH has used the Bayer Corporation's recommended limit of $0.5 \mathrm{mg} / \mathrm{m}^{3}$ for an 8-hour TWA and $1.0 \mathrm{mg} / \mathrm{m}^{3}$ as a $\mathrm{CL}$, which has also been adopted by the State of Oregon. ${ }^{41}$ A more conservative Swedish standard appears to be roughly on the basis of the general diisocyanate recommendation of $5 \mathrm{ppb}$ (TWA) and $20 \mathrm{ppb}$ (CL). The standard reads as follows: "hexamethylendiisocyanate-biurettrimer" (HDI BT), 5-minute STEL of $0.2 \mathrm{mg} / \mathrm{m}^{3}$, TLV TWA of $0.09 \mathrm{mg} / \mathrm{m}^{3}$."

\section{ANALYTICAL METHODS AND ISSUES}

The issues related to determining airborne isocyanate exposure are presented in detail in Chapter K of the NIOSH Manual of Analytical Methods. ${ }^{42}$ Portions of that text are presented below.

Accurate and sensitive determination of isocyanates is complex and difficult. The advantages and disadvantages of the various methods must be understood, in order to choose the most appropriate sampling and analytical method for a particular workplace environment. Isocyanates may be in the form of vapors or aerosols of various particle size; the species of interest are reactive and unstable; few pure analytical standards exist; and high analytical sensitivity is needed. In addition, numerous points exist in the sampling and analytical procedures where errors can be introduced. The selection of the most appropriate isocyanate method for a given workplace environment is based upon an evaluation of measurement accuracy, specificity, sensitivity, convenience, simplicity, and speed. These factors must be considered for the entire analytical measurement process including collection, derivatization, sample preparation, separation, identification, and quantification. For example, the faster the isocyanate product cures (isocyanate systems having half lives of a few minutes or less are considered fast cure), the more strongly an impinger is recommended for sampling. Also, an impinger is recommended for all aerosols having particle diameters greater than $2 \mu \mathrm{m}$ because it is believed that the poor mixing on filters results in poor derivatization efficiency. However, filters are recommended for sampling particles smaller than $2 \mu \mathrm{m}$ because they are collected inefficiently by impingers. 
Table 2. Comparison of NIOSH and OSHA Isocyanate Methods

\begin{tabular}{|c|c|c|c|c|c|}
\hline & NIOSH 5521 & NIOSH 5522 & NIOSH 2535 & OSHA 42/47 & NIOSH 5525 (draft)*43 \\
\hline \multicolumn{6}{|l|}{ Isocyanate } \\
\hline a) Monomers & $\begin{array}{l}\text { TDI, MDI, HDI, NDI, } \\
\text { HMDI }^{+}\end{array}$ & $\begin{array}{l}\text { TDI, MDI, HDI, } \\
\text { NDI, HMDI, }{ }^{+} \text {IPDI }\end{array}$ & TDI, HDI & $\begin{array}{l}\underline{42} \text { TDI, HDI } \\
\underline{47} \text { MDI }\end{array}$ & $\begin{array}{l}\text { TDI, HDI, MDI, } \\
\text { NDI, }^{\dagger} \text { HMDI, }{ }^{\dagger} \text { IPDI }\end{array}$ \\
\hline b) Oligomers & HDI & TDI, MDI, HDI & None & None & $\mathrm{HDI}, \mathrm{MDI}{ }^{\dagger}{ }^{\top} \mathrm{TDI}^{\dagger}$ \\
\hline Sampler & impinger & impinger & $\begin{array}{l}\text { coated glass } \\
\text { wool/opaque tube }\end{array}$ & coated GFF & $\begin{array}{l}\text { impinger; GFF; } \\
\text { impinger+GFF }\end{array}$ \\
\hline Reagent & MOPP in toluene & $\begin{array}{l}\text { tryptamine in } \\
\text { DMSO }\end{array}$ & $\begin{array}{l}\text { nitro reagent } \\
7 \mathrm{~d} 25^{\circ} \mathrm{C} \text { in dark }\end{array}$ & $\begin{array}{l}1-2 \mathrm{PP} \\
\underline{42} 0.1 \mathrm{mg} ; \underline{47} 1 \mathrm{mg}\end{array}$ & $\begin{array}{l}\text { MAP in butyl } \\
\text { benzoate }\end{array}$ \\
\hline Shelf Life & $7 \mathrm{~d} 0{ }^{\circ} \mathrm{C}$ & $6 \mathrm{mo} 25^{\circ} \mathrm{C}$ in dark & & $6 \mathrm{mo} 0{ }^{\circ} \mathrm{C}$ sealed & unknown \\
\hline $\begin{array}{l}\text { Sampling Rate } \\
\text { Volume }\end{array}$ & $\begin{array}{l}1 \mathrm{~L} / \mathrm{min} \\
5-500 \mathrm{~L}\end{array}$ & $\begin{array}{l}1-2 \mathrm{~L} / \mathrm{min} \\
15-360 \mathrm{~L}\end{array}$ & $\begin{array}{l}0.2-1 \mathrm{~L} / \mathrm{min} \\
2-170 \mathrm{~L}\end{array}$ & $\begin{array}{l}1 \mathrm{~L} / \mathrm{min} \\
15 \mathrm{~L}\end{array}$ & $\begin{array}{l}1-2 \mathrm{~L} / \mathrm{min} \\
1-500 \mathrm{~L}\end{array}$ \\
\hline Personal & No & No & Yes & Yes & Yes \\
\hline Vapor & Yes & Yes & Yes & Yes & Yes \\
\hline Particles $<2 \mu \mathrm{m}$ & No & No & No & Yes & $\begin{array}{l}\text { impinger: No } \\
\text { filter: Yes }\end{array}$ \\
\hline \multicolumn{6}{|l|}{ Particles $>2 \mu \mathrm{m}$} \\
\hline a) Slow-cure & Yes & Yes & No & $\mathrm{No}^{\ddagger}$ & $\begin{array}{l}\text { impinger: Yes } \\
\text { filter: } \mathrm{No}^{\ddagger}\end{array}$ \\
\hline b) Fast-cure ${ }^{\S}$ & Yes & Yes & No & No & $\begin{array}{l}\text { impinger: Yes } \\
\text { filter: No }\end{array}$ \\
\hline Sample Stability & $\begin{array}{l}7 \mathrm{~d} 25^{\circ} \mathrm{C}: 78 \% \\
7 \mathrm{~d} 4{ }^{\circ} \mathrm{C}: 88 \%\end{array}$ & $\begin{array}{l}28 \mathrm{~d} 25^{\circ} \mathrm{C} \text { in dark: } \\
95 \%-104 \%\end{array}$ & $14 \mathrm{~d} 25^{\circ} \mathrm{C}: 91 \%$ & $\begin{array}{l}15 \mathrm{~d} 22{ }^{\circ} \mathrm{C}: \\
\underline{42} 80 \%-86 \% \\
\underline{47} 94.8 \%\end{array}$ & unknown \\
\hline $\begin{array}{l}\text { Laboratory Sample } \\
\text { Preparation }\end{array}$ & $\begin{array}{l}\text { impinger: evap/ } \\
\text { redissolve in } \\
\text { methanol }\end{array}$ & none & $\begin{array}{l}\text { ultrasonic } \\
\text { extraction in } \\
\text { methanol }\end{array}$ & $\begin{array}{l}\text { extraction in } \\
\text { ACN/ DMSO, } 9 / 1\end{array}$ & $\begin{array}{l}\text { impinger: SPE } \\
\text { filter: extract or SPE }\end{array}$ \\
\hline Technique & HPLC/RP, isocratic & HPLC/RP, gradient & $\begin{array}{l}\mathrm{HPLC} / \mathrm{RP} \text {, } \\
\text { isocratic }\end{array}$ & HPLC/RP, isocratic & HPLC/RP, gradient \\
\hline $\begin{array}{l}\text { Detector } 1 \\
\text { LOD }^{* *}:\end{array}$ & UV@ 242 nm/ PDA & $\begin{array}{l}\text { FL ex } 275 \mathrm{~nm} \\
\text { em } 320 \mathrm{~nm}\end{array}$ & UV@ $@ 254$ nm & $\begin{array}{l}\text { FL ex } 240 \mathrm{~nm} \\
\text { em } 370 \mathrm{~nm}\end{array}$ & UV@253 nm \\
\hline $\begin{array}{l}\text { a) amount injected } \\
\text { b) } 15 \mathrm{~L} \text { air conc. }\end{array}$ & $\begin{array}{l}14 \mathrm{pmol} \\
1.2 \mathrm{ppb}\end{array}$ & $\begin{array}{l}0.7 \mathrm{pmol} \\
0.9 \mathrm{ppb}\end{array}$ & $\begin{array}{l}14 \mathrm{pmol} \\
0.9 \mathrm{ppb}\end{array}$ & $\begin{array}{l}0.2-1 \mathrm{pmol} \\
0.06-0.1 \mathrm{ppb}\end{array}$ & $\begin{array}{l}0.5 \mathrm{pmol} \\
0.08 \mathrm{ppb}\end{array}$ \\
\hline $\begin{array}{l}\text { Detector } 2 \\
\text { LOD }^{* *} \text { : } \\
\text { a) amount injected } \\
\text { b) } 15 \mathrm{~L} \text { air conc }\end{array}$ & $\begin{array}{l}\mathrm{EC}(+0.8 \mathrm{~V}) \\
0.5 \mathrm{pmol} \\
0.04 \mathrm{ppb}\end{array}$ & $\mathrm{EC}(+0.8 \mathrm{~V})$ & None & UV@254 nm & $\begin{array}{l}\text { FL ex } 250 \mathrm{~nm} \\
\text { em } 409 \mathrm{~nm} \\
\text { est. } \sim 5 \mathrm{fmol} \\
\text { est. } \sim 0.8 \mathrm{ppt}\end{array}$ \\
\hline Identification & $\begin{array}{l}\text { Monomer: Retention } \\
\text { Time } \\
\text { Aliphatic oligomers: } \\
\text { PDA }\end{array}$ & $\begin{array}{l}\text { Monomer: FL } \\
\text { Retention Time } \\
\text { Other isocyanate: } \\
\text { EC confirmation }\end{array}$ & Retention Time & Retention Time & $\begin{array}{l}\text { Monomer: Retention } \\
\text { Time Other } \\
\text { isocyanate: } \\
\text { UV/FL ratio }\end{array}$ \\
\hline
\end{tabular}

\footnotetext{
This method is under development; procedures may change somewhat pending validation. NIOSH [2002]. Method 5525, Isocyanates, total (MAP) Issue 1. NIOSH methods of analytical methods, 4th ed. Schlect PC and O'Connor PF (eds.). Cincinnati, Ohio: Department of Health and Human Services, Centers for Disease Control and Prevention, National Institute for Occupational Safety and Health, in press.

$\doteqdot$ Determination possible; lacks validation data.

$\doteqdot$ Usually underestimates concentration.

$\S \quad$ Half-life under several minutes.

** Instrumental limit of detection.
}

Abbreviations: $\mathrm{ACN}=$ acetonitrile; conc=concentration; $\mathrm{d}=$ days; $\mathrm{DMSO}=$ dimethyl sulfoxide; $\mathrm{EC}=$ electrochemical detector; em=emission; est=estimate; evap=evaporate; ex=excitation; $\mathrm{FL}=$ fluorescence detector; fmol=femtomole; $\mathrm{GFF}=\mathrm{glass}$ fiber filter; HDI=1,6-hexamethylene diisocyanate; HMDI=Methylene bis (4-cyclohexylisocyanate); HPLC=high performance liquid chromatography; IPDI=Isophorone diisocyanate; $\mathrm{L}=\mathrm{Liter} ; \mathrm{L} / \mathrm{min}=\mathrm{Liter}$ per minute; $\mathrm{LOD}=$ limit of detection; $\mathrm{MAP}=1$-(9-anthracenylmethyl)piperazine; $\mathrm{MDI}=4,4^{\prime}$-diphenylmethane diisocyanate; $\mathrm{mg}=$ milligram; $\mathrm{mo}=$ months; $\mathrm{MOPP}=1$-(2-methoxyphenyl)piperazine; nitro reagent $=N$-[(4-nitrophenyl) methyl $]$ propylamine; NDI=1,5-naphthalene diisocyanate; NIOSH=National Institute for Occupational Safety and Health; $\mathrm{nm}=$ namometer; OSHA=Occupational Safety and Health Administration; pmol=picomole; ppb=Parts (of a contaminant) per billion parts of air; $\mathrm{ppt}=$ parts per trillion; $\mathrm{PDA}=$ photodiode array detector; $1-2 \mathrm{PP}=1$-(2-pyridyl)piperazine; $\mathrm{RP}=\mathrm{reversed}$ phase; $\mathrm{SPE}=$ solid phase extraction; $\mathrm{TDI}=2,4-$ and/or 2,6-toluene diisocyanate; $\mathrm{UV}=\mathrm{ultraviolet}$ detector; $\mathrm{V}=\mathrm{Volume} ;{ }^{\circ} \mathrm{C}=\mathrm{degrees}$; Celcius; $\%=$ Percent; $\mu \mathrm{m}=$ micrometer 
Another issue is that impingers are considerably less convenient than filters for sampling and, in some cases, are not appropriate for personal sampling. Unfortunately, the need to measure highly reactive isocyanate species at low levels is many times in conflict with the desire of industrial hygienists and chemists to choose methods that are convenient to use in the field and are easy to run in the laboratory.

Table 2 summarizes NIOSH and OSHA isocyanate methods and method selection for a given workplace environment. The selection of the most appropriate isocyanate method depends upon the isocyanate species, its physical state, its cure rate, the sensitivity required, and other factors shown in Table 2. This information is used to select methods for NIOSH research studies and HHEs and is also provided when employers, industrial hygienists, or laboratories request NIOSH technical assistance on isocyanate methods. Direct-reading instruments can be used to measure isocyanate concentrations in the field, but they have limitations just like the laboratory methods. The direct-reading instruments use a colorimetric tape with a photoanalyzer to quantify the color change. They are only appropriate for certain monomers in the vapor phase, and other isocyanates and non-isocyanates can interfere.

Obvious from the above discussion, more research is needed to resolve the limitations of current sampling and analytical methods. Such research is ongoing at NIOSH and elsewhere in government, academic, and private organizations. NIOSH is currently proposing a new sampling method (NIOSH 5525, see Table 2$)^{43}$ that is more sensitive and selective than previous methods and that can be used for PBZ sampling. This method was recently evaluated by researchers at the University of Massachusetts, Lowell, ${ }^{44}$ and will be issued in the next supplement for the NIOSH Manual of Analytical Methods. Chapter $\mathrm{K}$ of this manual (referenced at the beginning of this section) is currently being updated by NIOSH chemists to include more discussion of this new method.

\section{RECOMMENDATIONS}

Any HHEs that determine a potential for isocyanate exposures offer certain recommendations for respiratory and dermal protection, employee education, and medical surveillance. The recommendations may vary slightly on the basis of the specific HHE. Often other site-specific recommendations are made, but the ones routinely offered are as follows:

1. Whenever there is potential for exposure to diisocyanates, even concentrations below the NIOSH REL, NIOSH recommends that employees be supplied with supplied-air respiratory protection. (Negative pressure air-purifying respirators are not recommended since diisocyanates have poor odor warning properties.) Also, there should be a respiratory protection program.

2. NIOSH investigators recommend that dermal exposures to isocyanate-containing substances be prevented.

Employers should provide protective clothing, gloves, and footwear that is impervious to isocyanate-containing compounds. The protective clothing should either be disposed or laundered after each use (e.g., at the end of the work shift). The gloves should be elbow-length and made of an isocyanateresistant material. Face-shields and aprons should be used whenever there is a possibility of a splash or a spill of liquids containing isocyanatecontaining materials. The open points at the interface between different forms of protective clothing, e.g., the opening that forms between the sleeve of a protective suit and a glove, should be sealed to prevent exposure through the interface. A common and effective method for sealing these interfaces is to use duct tape to join the two different forms of protective clothing. 
3. NIOSH recommends that employers provide workers with appropriate training on the inhalation and dermal exposure hazards associated with isocyanate-containing materials and on the proper use of personal protective equipment (PPE) associated with protection from these exposures.

NIOSH recommends both preplacement and periodic medical surveillance programs for all workers potentially exposed to diisocyanates.

The preplacement examinations should consist of detailed medical and work histories with emphasis on pre-existing respiratory and/or allergic conditions, a physical examination that centers on the respiratory tract, a baseline pulmonary function test that measures forced expiratory volume in one second $\left(\mathrm{FEV}_{1}\right)$ and forced vital capacity (FVC), and a judgement on the worker's ability to wear a suppliedair respirator. Workers should be provided with annual examinations that update the medical and work histories and measure the worker's FEV 1 and FVC.
4. NIOSH recommends that empoloyers conduct industrial hygiene (IH) surveys on all workers potentially exposed to isocyanates.

These surveys should contain both inhalation and dermal exposure evaluations and should be conducted on an annual basis or when there are changes in the process or engineering controls. A sufficient number of samples should be collected to characterize each employee's exposure and to characterize isocyanate emissions from a given process, operation, machine, etc. These surveys should encompass both routine (e.g., normal operations and scheduled maintenanace) and nonroutine (e.g., repair activities associated with breakdowns or malfunctions) work activities. Task oriented exposure assessments should be used to determine the isocyanate exposure levels associated with specific tasks within an operation or shift.

5. All medical and IH records should be kept by the employer for a time period of no less than 30 years. 


\section{ISOGYANATE HHE SUMMARIES ORGANIZED BY PROCESS}

\section{Ad hesives}

\section{HETA 94-0027 \\ May 1994}

Requester: Union

Method(s): NA

Range of isocyanates: NA

Purpose: To investigate complaints from underground coal miners of illness after exposure to rock glues Keywords: SIC 1222 (Bituminous Coal Underground Mining), rock glue, diphenylmethane diisocyanate, isocyanates

Abstract: NIOSH conducted this HHE to investigate complaints from underground coal miners of illnesses, including respiratory problems, asthma, and skin irritation, after exposure to rock glues in the course of their work duties. NIOSH was requested to provide guidance in establishing a company medical surveillance program for those workers with exposure to rock glue adhesives containing isocyanates. NIOSH reviewed and concurred with the proposed safety precautions to be taken during the application of the rock glue.

Recommendations included substituting non-isocyanate-containing products where feasible and providing protective clothing made from laminates to protect against dermal exposure to isocyanates.

\section{HETA 97-0217-2667 December 1997}

Requester: Management Method(s): NIOSH 5522

Range of isocyanates: two GA samples$20.1 \mu \mathrm{g} / \mathrm{m}^{3}$ and $30.7 \mu \mathrm{g} / \mathrm{m}^{3} \mathrm{ppm}$ MDI Purpose: To investigate workers' exposures and symptoms, including dizziness and sleepiness, that were believed to be related to a hot melt adhesive process used in the production of residential doors

* Keywords: SIC 2431 (Millwork), door manufacturing, hot adhesive, acetone, methylene bisphenyl diisocyante, methylene cholride, toulene, sleepiness, dizziness, ventilation

\footnotetext{
* at the conclusion of an HHE, the NIOSH investigators provide keywords for inclusion in the HHE database
}

Abstract: NIOSH conducted an HHE to investigate workers' exposures and symptoms, including dizziness and sleepiness, that were believed to be related to a hot melt adhesive process used in the production of residential doors. Confidential medical interviews were conducted with employees in the door assembly area. The two GA air samples collected for MDI were below current occupational exposure limits. The local exhaust ventilation of the roller machine was operating. There was very little air movement in the door assembly area, and the fans that were used were blowing directly toward the assembly employees. In addition, solvent vapors from the adjacent production area were entering the door assembly area. Because of continued health complaints among employees and low concentrations of VOCs in the door assembly area, this company should consider adding LEV to the area. Additionally, replacement air from a clean area or from outside should be added to compensate for the air being exhausted and to provide additional ventilation. 


\section{Decomposition Products}

\section{HETA 89-0360 \\ December 1991}

Requester: Union

Method(s): NA

Range of isocyanates: NA

Purpose: To investigate health complaints from operators in a trilaminator department and adjacent departments

Keywords: SIC 2396 (Automotive

Trimmings, Apparel Findings, and Related

Products), urethane foam, antimony, TDI

Abstract: NIOSH conducted an HHE at an automobile seat manufacturer to investigate health complaints from operators in the trilaminator department and sewing machine operators in an adjacent department. Workers reported that they were experiencing chronic skin and eye irritation and acute and chronic respiratory problems. NIOSH reviewed environmental sampling completed by the manufacturer, and conducted laboratory experiments on bulk samples of the urethane foam and powder adhesives. At the time of the NIOSH site visit, 10 workers operated two trilaminator units. Past IH surveys had found TDI air concentrations to be low during normal operation of the trilaminators. However, the potential for worker exposure was increased during fires (which occurred about once a month) because the LEV system was deactivated until the fire was extinguished. The data from the NIOSH laboratory analyses, along with the data from the previous studies provided by the manufacturer, clearly demonstrated that TDI is released when urethane foam is heated, that the concentration of TDI released increases as the temperature increases, and that high concentrations may be released during fires. In addition, the NIOSH analyses show that other chemicals are released when urethane foam and powder adhesive are heated. As with TDI, concentrations of the other compounds increase as the temperature increases. The acute respiratory symptoms and mucous membrane irritation reported during fires in the trilaminator and Lincoln
Base departments were consistent with exposure to smoke and other fire-generated emissions (e.g., TDI, formaldehyde,

acetaldehyde, acrolein, benzene, which are known respiratory and mucous membrane irritants). Chronic respiratory problems (e.g., asthma-like symptoms and bronchitis) may have been related to exposure to smoke and fire-generated emissions. It was also possible that a few individuals may have developed TDI-related occupational asthma. NIOSH recommended that the manufacturer investigate alternatives to the present system that results in fires and contamination of workplace air, that there be a better fire-emergency plan, and that the company follow all the standard isocyanate recommendations if isocyanate exposures are not eliminated from this workplace.

\section{HETA 91-0053-2320 May 1993}

Requester: Union

Method(s): NIOSH 5521

Range of isocyanates: $<1.7 \mu \mathrm{g} / \mathrm{m}^{3}$ (below MDC)

Purpose: To investigate possible employee exposures to hazardous residues during railroad tank car repair Keywords: SIC 4789 (Transportation Services, not elsewhere classified), railroad car repair, tank cars, arsenic, chromium, welding, cutting, air arc gouging, isocyanates

Abstract: NIOSH conducted this HHE to evaluate possible employee exposures to hazardous residues during railroad tank car repair. Ten GA air samples were collected during cutting and burning on polyurethane foam-insulated chlorine cars, but no isocyanates were detected $\left(<1.7 \mu \mathrm{g} / \mathrm{m}^{3}\right)$. However, investigators determined from the bulk samples that there was potential for exposure to polyisocyanate foam decomposition products. NIOSH provided recommendations for engineering and administrative controls to prevent isocyanate and other hazardous exposures. 


\section{HETA 94-0312-2512 June 1995}

Requester: Joint Employee-Management Method(s): NIOSH 5522 and NIOSH 2535 Range of isocyanates: ND (TDI) Purpose: To investigate respiratory symptoms potentially associated with isocyanate exposures during brazing and welding operations

Keywords: SIC 3677 (Electronic Coils, Transformers, and Other Inductors), isocyanates, diisocyanates, TDI, transformers, occupational asthma, brazing, welding

Abstract: NIOSH conducted this HHE to investigate respiratory symptoms potentially associated with isocyanate exposures during brazing and welding operations. In addition, a variety of other health effects were reported. The industrial hygienists reviewed MSDSs and manufacturing processes and evaluated employee exposure to TDI. PBZ air samples were collected during simulated brazing operations at the entrance of the flexible duct of the portable filtration unit, one foot prior to the entrance, and in and near the exhaust. TDI was ND in any of the air samples. The medical investigators distributed and reviewed respiratory symptom/allergy questionnaires, reviewed the OSHA illness and injury log, workers' compensation claims, and employee medical records, and interviewed workers. From January 1992 through December 1994, six incidents occurred involving respiratory problemstwo were described as asthma attacks, two were for smoke inhalation, one was recorded as "respiratory problems," and one was recorded as allergic pneumonitis. In the past year, 20 (14\%) of the 138 respondents reported experiencing three or more respiratory symptoms including shortness of breath, difficulty breathing, chest tightness, and wheezing; 9 (7\%) reported physiciandiagnosed asthma; 21 (15\%) respondents reported dermatologic symptoms. The NIOSH medical investigators interviewed 20 workers. The most prevalent symptoms among the 15 (75\%) symptomatic workers were upper respiratory irritation and skin problems such as rashes, hives, and eczema. On the basis of the data collected during this survey, the NIOSH investigators did not find evidence of a current health hazard from brazing-related TDI exposure and were unable to determine the frequency and severity of past TDI exposures. Workers did appear to have respiratory symptoms that could be associated with the brazing and welding operations.

Exposure to the many constituents of welding and brazing fumes is a possible cause of these symptoms. Recommendations were offered to reduce workers' exposures when performing these operations including (1) all welding and brazing operations / stations should be equipped with fixedstation LEV systems that exhaust the air outside of the workplace and (2) a qualified heating, ventilation, and air conditioning firm should be contracted to conduct a mechanical system audit of the ventilation system to verify that the system is adequately sized and designed for current application.

\section{Foaming}

\section{HETA 89-0278-2035 April 1990}

Requester: Government

Method(s): Proposed NIOSH 5525 (currently in review) $)^{43}$

Range of isocyanates: ND to $0.2 \mu \mathrm{g} / \mathrm{m}^{3} \mathrm{MDI}$ Purpose: To evaluate exposures and health effects from MDI among workers of a jewelry facility

Keywords: SIC 3911 (Misc. Manufacturing not classified elsewhere e.g., jewlrey, silverware etc.), MDI, isocyanates, foam insulation, asthma, HP, MDI-induced respiratory disease

Abstract: NIOSH responded to a local health department request to evaluate exposures and health effects among workers of a jewelry facility where foam insulation containing MDI had been applied. Five days after the application ceased, NIOSH investigators collected air samples, administered questionnaires, and offered 
medical evaluations to those who reported asthma-like symptoms on the selfadministered questionnaires. Seven of the sixteen GA air samples had detectable quantities of MDI, ranging from 0.1 to $0.2 \mu \mathrm{g} / \mathrm{m}^{3}$, which were all well below the relevant exposure limits. Because of the timing of the request, it was not possible to estimate exposures during the spraying application. Ninety-six percent (75/78) of the workers that worked during the week of application completed theself-administered symptom questionnaire, and 13 were identified as having probable MDI-induced respiratory disease. Investigators concluded that MDI exposures probably occurred during the insulation application, and they provided recommendations for the prevention of future exposures and guidance for workers with persistent respiratory symptoms.

\section{HETA 89-0312 April 1990}

Requester: Government Method(s): NIOSH 5521

Range of isocyanates: ND for MDI monomer and MDI-based polyisocyanates but there were problems with the MDI-based polyisocyanate analyses

Purpose: To evaluate worker exposure to MDI at an animal taxidermy manufacturer Keywords: SIC 2759 (Commercial Printing, not elsewhere classified), MDI, fluorinated hydrocarbons, diisocyanates

Abstract: This HHE was conducted to evaluate worker exposure to MDI at a manufacturer that makes animal head forms for use in big game taxidermy. The heads are made using a 2-part foam system. Part " $\mathrm{A}$ " contains MDI, and Part " $B$ " contains fluorinated hydrocarbons and tertiary aliphatic amines. The two liquids are mixed in a bucket, poured into molds, and allowed to sit at room temperature while windows and doors are kept open to provide ventilation. NIOSH collected $5 \mathrm{GA}$ air samples in the building. No MDI was detected in any of the air samples. The sampling and analytical
LOD was reported to be about $2 \mu \mathrm{g} / \mathrm{m}^{3}$. Investigators reported that it should not be assumed that there is no exposure to MDI despite the results of the test; this analytical method was still questionable for detecting MDI-based polyisocyanate at the time of the survey. Also, once a person becomes sensitized to MDI, exposure at very low concentrations may trigger illness, and therefore any future exposures must be avoided. Guidance included the standard isocyanate recommendations and also the addition of engineering controls such as process enclosures or LEV to reduce risk of exposure.

\section{HETA 90-0011-2034 April 1990}

Requester: Management

Method(s): NIOSH 5521

Range of isocyanates: ND to $320 \mu \mathrm{g} / \mathrm{m}^{3} \mathrm{MDI}$ (short-term samples), ND for MDI-base polyisocyanate

Purpose: To characterize worker exposure to isocyanates during use of a polyurethane foam system in the shipping department Keywords: SIC 3491 (Industrial Valves), MDI, polyurethane foam, Instapak $40^{\mathrm{TM}}$, respiratory protection, short-term exposures

Abstract: NIOSH conducted this HHE to determine the exposures to workers using a polyurethane foam system in a shipping department. The foam was a two-component system that contained MDI and MDI- based polyisocyanate, and was applied with a spray gun. The actual packaging of valves took approximately 30 to 45 minutes, during which the foam system was used for about 5 minutes. Thus, MDI entered the work atmosphere as a point source emission and the exposure was intermittent in nature. TWA and short-term exposure monitoring was performed in the packaging area using NIOSH Method 5521. TWA air sampling equipment was located in the packaging station work area and in surrounding work areas at varying distances from the polyurethane foam application area. All of the TWA air samples measured nondetectable levels of MDI and MDI-based poly- 
isocyanate. Conversely, the short-term exposure sampling did measure substantial levels of MDI but did not detect any MDI-based polyisocyanate. Concentrations of MDI ranged from ND to $320 \mu \mathrm{g} / \mathrm{m}^{3}$, with 2 of the 7 samples being above the OSHA and NIOSH CLs for MDI of $200 \mu \mathrm{g} / \mathrm{m}^{3}$. On the basis of this survey, the NIOSH investigators concluded that a health hazard existed from short-term exposure to MDI when applying the foam. Recommendations were made in this report to either eliminate the use of the polyurethane foam system, or to use engineering controls and PPE to protect the workers. All the standard isocyanate recommendations were made.

\section{HETA 90-0175 August 1992}

Requester: Employee

Method(s): NIOSH 5521

Range of isocyanates: ND (MDI monomer and MDI-based polyisocyanate)

Purpose: To investigate employee exposures to MDI in the foam operations and adjacent departments

Keywords: SIC 3632 (Household

Refrigerators and Home and Farm Freezers) MDI

Abstract: NIOSH conducted this HHE at a refrigerator manufacturer to investigate employee exposures to MDI in the foam operations and assembly and subassembly operations in adjacent departments because some workers had developed occupational asthma as a result of exposures to MDI. Investigators conducted full-shift and short-term $\mathrm{GA}$ air monitoring to characterize exposures to MDI and MDIbased polyisocyanate in the foam application and adjacent departments. Full-shift sampling was performed by placing area air sampling equipment in foam application areas and in adjacent departments. The short-term exposure monitoring was performed by holding the air sampling equipment in or near the breathing zone of the workers or by placing the equipment as close as possible to the foam fixture head. Because the sampling equipment contained liquid solutions of toluene, the equipment was not placed directly on the workers. Efforts were made to obtain samples at either worst-case locations or at workstations where workers spent most of their time. On the basis of the limits of detection (LOD) for the analytical method, neither MDI nor MDI-based polyisocyanate was present at concentrations above $1 \mu \mathrm{g} / \mathrm{m}^{3}$ on full-shift air samples or $20 \mu \mathrm{g} / \mathrm{m}^{3}$ on short-term (10 to 15 minute) air samples. Subsequent resampling by a consultant showed similar results. Although the overall level of MDI exposure appeared to be low, workers who are sensitized to MDI may suffer effects even at levels below NIOSH LOD. NIOSH recommended that workers with potential for exposure to MDI should have preplacement and periodic medical examinations to determine if any medical conditions exist that could be aggravated by exposure to isocyanates. Also, all of the other standard isocyanate recommendations were provided.

\section{HETA 90-0277-2487 February 1995}

Requester: Union

Method(s): NA

Range of isocyanates: NA

Purpose: To investigate exposures potentially related to halovision in workers at a polyurethane foam production plant Keywords: SIC 2531 (Seats: Automobile), polyurethane foam, organic amines, diethanol amine, triethylene diamine, DABCO, bis(2-dimethylaminoethyl) ether, NIAX ${ }^{\circledR}$ A99, triethyl urea, halovision, visual disturbance, diisocyanates, TDI, asthma

Abstract: NIOSH conducted this HHE because workers exposed to amine catalysts used in polyurethane foam production were experiencing halovision. Although isocyanate sampling was not requested, investigators noted that the foam manufacturing process used resins that contained TDI and that the employee questionnaire revealed that greater than $30 \%$ of the respondents reported 
experiencing respiratory symptoms that were consistent with isocyanate exposure. For those reasons, NIOSH provided the standard isocyanate HETA Program recommendations to this facility.

\section{HETA 91-0386-2427 May 1994}

Requester: Government Method(s): NIOSH 5521

Range of isocyanates: $<1.6 \mu \mathrm{g} / \mathrm{m}^{3}$ MDI monomer (below MQC)

Purpose: To investigating a possible health hazard from exposure to MDI at an artificial plant manufacturing facility

Keywords: SIC 3999 (Manufacturing Industries, not elsewhere classified), artificial flower arrangements manufacturing, polyurethane foam, diphenylmethane diisocyanate, HP, MDI

Abstract: NIOSH conducted this HHE to investigate a possible health hazard from exposure to MDI at an artificial plant manufacturing facility. The request was prompted by the death of a former employee who had developed a disease consistent with HP after working with MDI at the plant. The facility used a MDI-based polyurethane foam to provide a rigid support for artificial plant arrangements. NIOSH investigators found detectable concentrations of monomeric MDI in two of the five full-shift GA air samples collected in impingers; however, these concentrations were below the LOQ. The MDC was $0.6 \mu \mathrm{g} / \mathrm{m}^{3}$, and the MQC was $1.6 \mu \mathrm{g} / \mathrm{m}^{3}$ for the samples. The six impingers used for short-term personal sampling did not detect monomeric MDI. The detection limit for these samples was about $20 \mu \mathrm{g} / \mathrm{m}^{3}$. Vapors/aerosols were observed rising into the faces of workers working with the foam. This observation and a chemical smoke tube test indicated that the ventilation systems in the foaming areas were not adequate for preventing worker exposure to MDI. Skin contact with the curing foam was also noted during the survey. The medical portion of the survey consisted of a medical questionnaire, occupational and exposure histories, spirometry, and serial peak flow measurements.

Individuals who reported high exposure to the polyurethane foaming process were more likely to report work-related nasal and eye irritation than were individuals in the other exposure categories. Self-reported exposure to the foaming process was not associated with any other symptoms, nor was it related to pulmonary function, as measured by spirometry and serial peak flow monitoring. Thirty-five prior workers participated in a separate medical questionnaire. Sixteen prior workers had spirometry testing, and all had normal results, including two of the four who said they had left work because of a respiratory problem. There was no evidence of impaired pulmonary function among former workers who participated in this study. There was no apparent relationship between chronic pulmonary impairment, as assessed by spirometry, or reactive airway disease, as measured by peak flow variability, and working with the foaming system. Current workers who work directly with the polyurethane foaming system were found to have a substantial prevalence of work-related nasal and ocular irritation, suggesting that there is ongoing exposure to an irritant. The air sampling did not indicate concentrations of MDI above the exposure standards, but because of the potential for isocyante exposures, investigators provided all the standard isocyanate recommendations. 


\section{HETA 94-0055} Jully 1996

Requester: Employee

Method(s): GMD Sure-Spot ${ }^{\mathrm{TM}}$ Test cards and OSHA 47 (by a consultant prior to the HHE) Range of isocyanates: 15-minute samples ranged from ND to $37.86 \mu \mathrm{g} / \mathrm{m}^{3}$ MDI monomer (Note: OSHA 47 often underestimates concentrations)

Purpose: To evaluate exposures and possible health effects associated with the use of a two-component polyurethane foam system

Keywords: SIC 3585 (Air-Conditioning and Warm Air Heating Equipment and Commercial and Industrial Refrigeration Equipment), MDI, asthma, respiratory sensitization, polyurethane foam, soft drink dispensers, ice chests

Abstract: NIOSH conducted this HHE to evaluate exposures and possible health effects associated with the use of a twocomponent polyurethane foam system, which contained MDI and MDI-based polyisocyanates. An independent consultant had performed two types of isocyanate short-term air sampling prior to the $\mathrm{HHE}$, and the results ranged from ND to $37.8 \mu \mathrm{g} / \mathrm{m}^{3}$ MDI. NIOSH investigators did not perform any air sampling because the consultant data documented the presence of isocyanates, and previous NIOSH HHEs and other studies had documented MDI and MDI-based polyisocyanate exposures and work-related asthma from injection foaming processes. Based upon the employee interviews and review of medical records, at least two workers had occupational asthma, one employee possibly had occupational asthma, and one employee had underlying asthma that was reportedly exacerbated by the workplace. Investigators provided the standard isocyanate recommendations.

\section{HETA 94-0124-2470 November 1994}

Requester: Employee

Method(s): NIOSH 5522

Range of isocyanates: ND to $6 \mu \mathrm{g} / \mathrm{m}^{3}$ MDI monomer, 2 to $13 \mu \mathrm{g} / \mathrm{m}^{3}$ TRIG, ND to $38 \mu \mathrm{g} / \mathrm{m}^{3}$ MDI oligomer Purpose: To evaluate potential chemical exposures from polyurethane foam injection processes

Keywords: SIC 3632 (Household

Refrigerators and Home and Farm Freezers) MDI, blowing agents, fluorotrichloromethane, condensation aerosol

Abstract: NIOSH conducted this HHE to evaluate potential chemical exposures from polyurethane foam injection processes. The request stated that health effects among some workers, including eye and throat irritation, asthma, emphysema, cancer, and heart disease, resulted from exposure to workplace chemicals and environmental tobacco smoke. NIOSH investigators conducted site-visits and area air sampling for monomeric and oligomeric MDI at six locations where polyurethane foam was being injected into refrigerator doors and cabinets. At each location, six sampling trains were used to differentiate between MDI vapor and condensation aerosol. Monomeric MDI concentrations ranged from ND to $6 \mu \mathrm{g} / \mathrm{m}^{3}$, less than the NIOSH REL of $50 \mu \mathrm{g} / \mathrm{m}^{3}$. TRIG concentrations were calculated (range: 2 to $13 \mu \mathrm{g} / \mathrm{m}^{3}$ ); these concentrations were less than the 8-hour TWA UK-HSE Common Control Limit of $20 \mu \mathrm{g} / \mathrm{m}^{3}$. The highest concentration $\left(13 \mu \mathrm{g} / \mathrm{m}^{3}\right)$ was found at the foam-in-place injection area. Considering the possible low analytical recovery for oligomeric MDI, the concentrations of oligomer and TRIG may be underestimated. However, if a worst-case $60 \%$ recovery is assumed, only the sample collected at the foam-in-place location could be near the exposure limit. No MDI was found on the treated filters or back-up bubblers (except one bubbler), suggesting little or no condensation aerosol was present. 
A health hazard from overexposure to MDI was not determined during the NIOSH evaluation.

\section{*HETA 97-0084-2669 December 1997}

Requester: Management

Method(s): NIOSH 5522

Range of isocyanates: Spray painting5.1 to $9.6 \mu \mathrm{g} / \mathrm{m}^{3}$ 2,4-TDI monomer, 7.4 to $17.9 \mu \mathrm{g}-\mathrm{NCO} / \mathrm{m}^{3}$ TRIGs, ND 2,6-TDI monomer; packaging-ND MDI monmer, ND to $15.5 \mu \mathrm{g} / \mathrm{m}^{3}$ MDI oligomer, $<9.8 \mu \mathrm{g}-\mathrm{NCO} / \mathrm{m}^{3}$ TRIGs

Purpose: To document worker exposure to isocyanates during spray painting and packaging processes

Keywords: SIC 3519 (Internal Combustion Engines, not elsewhere classified), noise, isocyanates, metal working fluids, TDI and MDI, total reactive isocyanate TRIG, toluene, xylene, formaldehyde, inorganic acids, ammonia, lead

* also included in surface coating processes

Abstract: NIOSH conducted this HHE to document worker exposure to isocyanates during spray painting and packaging of engine control devices. Monitoring for TDI and MDI monomers and oligomers and TRIGs was conducted. Area air sampling results for TDI during spray-painting operations ranged from 5.1 to 9.6 for 2,4 TDI monomer, and 7.4 to $17.9 \mu \mathrm{g} \mathrm{NCO} / \mathrm{m}^{3}$ for TRIGs. No 2,6-TDI monomer was detected. These data indicate that area 14 isocyanate levels are low for spray-painting operations, especially when compared to the ACGIH TLV for TDI (8-hour TWA of $\left.36 \mu \mathrm{g} / \mathrm{m}^{3}\right)$ and the UK-HSE standard for TRIG (8-hour TWA of $20 \mu \mathrm{g} \mathrm{NCO} / \mathrm{m}^{3}$ ). The low levels indicated that the spray booth was effectively containing the isocyanates. Area air samples collected for MDI during packaging operations did not detect MDI monomer but detected oligomer concentrations ranging from ND to $15.5 \mu \mathrm{g} / \mathrm{m}^{3}$. The TRIG concentrations were all below $9.8 \mu \mathrm{g} \mathrm{NCO} / \mathrm{m}^{3}$. Although MDI concentrations were low, the design of the local exhaust systems for the packaging needed improvements. NIOSH provided the standard isocyanate recommendations.

\section{HETA 98-0011-2801 July 2000}

Requester: Union

Method(s): Proposed NIOSH 5525 (currently in review) $)^{43}$

Range of isocyanates: $1.40 \mu \mathrm{g} / \mathrm{m}^{3}$ to $2.75 \mu \mathrm{g} / \mathrm{m}^{3}$ TDI in air; $1.74 \mu \mathrm{g} / 1$ and $1.77 \mu \mathrm{g} / \mathrm{l} \mathrm{TDA}$ in urine (creatinine-corrected). Purpose: To evaluate potential exposures to TDI in a plant that produced flexible polyurethane foam cushions for automobile seats

Keywords: SIC 3714 (Motor vehicle parts and accessories), diisocyanates, occupational asthma, diisocyanate-induced sensitization, allergic contact dermatitis, TDI, TDA, formaldehyde, hydrocarbon solvents, Bis (2-dimethylaminoethyl) ether, NIAX ${ }^{\circledR}$, respiratory irritants, foam-manufacturing

Abstract: NIOSH investigated a plant that produced flexible polyurethane foam cushions for automobile seats. The union request indicated that five workers had been diagnosed with cancer over the last 4 years, and that current workers were concerned that these cancers might be caused by workplace exposures, especially to TDI, the primary chemical constituent used to make the flexible foam used for automotive seat cushions. The union later noted that 83 workers had recently completed a health and safety survey and that various health symptoms were reported that were consistent with exposure to diisocyanates.

Two initial site visits involved interviews, process and work practice observations, records reviews, and air sampling for hydrocarbons. Some hydrocarbon sampling was conducted during the subsequent visit in May 1999, but the major study was to evaluate TDI exposures and their relationship to the prevalence of occupational asthma, airway hyper-responsiveness, allergic sensitization to TDI, and diisocyanaterelated allergic contact dermatitis. NIOSH investigators also conducted an evaluation of the five reported cancers. 
One hundred fourteen (39\%) of the 290 workers completed medical questionnaires, 100 provided blood samples for measuring TDI-specific antibodies, 65 provided serial peak flow records for assessing airway hyper-responsiveness, and 26 participated in skin patch testing to assess allergic contact dermatitis.

Asthma and work-related asthma were defined from questionnaire responses using standard epidemiologic definitions; cases defined in this way may not meet standard clinical definitions of asthma. Twenty-two percent (25/114) of the participants met the case definition for asthma, and 18\% (20/114) met the case definition for work-related asthma.

Production work (PRR $=3.40 ; 95 \%$ $\mathrm{CI}=0.92-39.52)$ and ever working with TDI (PRR $=2.31$; 95\% CI =0.34-123.20) were both associated with asthma. Production work $(\mathrm{PRR}=2.66 ; 95 \% \mathrm{CI}=0.65-29.16)$ and ever working with TDI $(\mathrm{PRR}=1.83$; $95 \% \mathrm{CI}=0.25-92.75$ ) were also associated with work-related asthma. However, these associations were not statistically significant ( $\mathrm{p}<0.05)$. Of the 59 peak flow participants whose peak flow records were suitable for analysis, $25(42 \%)$ met the definition for airway hyper-responsiveness. Of the 25, 8 had a work-related pattern, 5 had a non-work related pattern, and no pattern could be discerned for the remaining 12 .

Eighty-two (72\%) of participants met the case definition for work-related mucous membrane (nose and eye) irritation symptoms. Production line work (PRR $=1.57 ; 95 \%$ $\mathrm{CI}=1.05-10.05)$ and ever working with TDI $(\mathrm{PRR}=1.88 ; 95 \%$ CI 0.97-23.08) were associated with mucous membrane symptoms $(\mathrm{p}<0.05)$.

Antibody test and skin patch testing results did not show an immune response to TDI or the presence of TDI-related allergic contact dermatitis. Of the 100 individuals providing blood for antibody testing, two had an elevated TDI-specific immunoglobulin class G (IgG) antibody level, and none had an elevated TDI-specific immunoglobulin class E (IgE) antibody level. Of the 26 indi- viduals participating in skin patch testing, none developed skin reactions to any of the test allergens either 48 or 96 hours after patch test application.

PBZ air samples were calculated for each worker participating in the medical evaluation. Additionally, PBZ samples were obtained for a random sample of workers who did not participate in the medical evaluation. TDI area air sampling was also conducted. Workers who participated were also asked to provide an end-of-shift urine sample, which was analyzed for a metabolite of TDI exposure, TDA.

The highest TDI $(2,4-, 2,6-$ and total TDI) exposures were found among production line workers. Demold workers had the highest mean total TDI exposures $\left(2.75 \mu \mathrm{g} / \mathrm{m}^{3}\right)$, followed by insert workers $\left(2.37 \mu \mathrm{g} / \mathrm{m}^{3}\right)$, mechanics $\left(1.49 \mu \mathrm{g} / \mathrm{m}^{3}\right)$, and utility workers $\left(1.40 \mu \mathrm{g} / \mathrm{m}^{3}\right)$. However, TDI concentrations for all PBZ and area samples were below the current ACGIH TLV of $36 \mu \mathrm{g} / \mathrm{m}^{3}$. A sample stability problem arose when TDI air samples collected in May 1999 underwent storage for a 3-month period; a $12 \%$ to $14 \%$ decline in TDI concentration between analysis in September and October 1999 was identified in these samples. However, reanalysis of the samples did not support a continuous sample stability problem, and only minor concentration declines were identified between the initial and subsequent TDI analyses. Analysis of urine TDA concentrations in workers demonstrated that production line workers (primarily demold and insert workers) had the highest TDA levels; creatinine-corrected mean urine total TDA levels among demold workers and insert workers were $1.77 \mathrm{mg} / \mathrm{l}$ and $1.74 \mathrm{mg} / \mathrm{l}$, respectively. Statistically significant correlations were found between total TDI exposure and both uncorrected $(R=0.30$, $P=0.007)$ and creatinine-corrected $(R=0.35, P=0.002)$ urine 2,4-TDA levels.

Although airborne exposures to TDI were below RELs, respiratory, mucous membrane, and skin problems were noted in this worker population and these symptoms were 
associated with indicators of TDI exposure. The strength of this association, however, was limited by the low participation rate of the study. Insert and demold workers had higher environmental TDI exposure levels compared with offline workers and nonproduction personnel, and subsequently demonstrated higher urine TDA levels. The reported cancers among workers were not consistent with a work-related etiology, because of the variety of cancers noted, the limited carcinogenic potential of the compounds identified, and the low exposure levels measured for each compound. Recommendations included following proper medical surveillance procedures for workers exposed to TDI, improving ventilation, improving the availability and usage of PPE, and following existing safety and health guidelines.

\section{HETA 99-0065-2780 December 1999}

Requester: Employee

Method(s): Proposed NIOSH 5525 (currently in review) $)^{43}$

Range of isocyanates: $1.1 \mu \mathrm{g} / \mathrm{m}^{3}$ and $2.3 \mu \mathrm{g} / \mathrm{m}^{3} \mathrm{MDI}$

Purpose: To evaluate exposures to MDI during the use of an Instapak ${ }^{\circledR}$ foam-in-bag packaging system

Keywords: SIC 3714 (Motor Vehicle Parts and Accessories); isocyanates, MDI, polyurethane foam, packaging, automobile parts

Abstract: NIOSH investigated an Instapak foam-in-bag packaging system, marketed under the trade name of Speedy Packer ${ }^{\mathrm{TM}}$, at a manufacturer of truck transmissions. The plant began packaging parts in polyurethane foam in 1988 using an Instapak $^{\circledast}$ foam-in-place system. An employee using the foam-in-place packaging system had to be removed from the job after 2 days due to respiratory symptoms described by the affected employee as "constricting of the throat and wheezing." A different person began using the system and worked without incident. In February 1999, the foam-in-place system was replaced with the foam-in-bag system currently used in the warehouse. NIOSH investigators conducted a site visit in April 1999 to observe how the packaging system was used, learn about the occupational health programs in place for users of the packaging system, and obtain environmental measurements for MDI and MDI oligomers. One person worked directly with the foam-in-bag system and several workers worked adjacent to the foaming area at distances of approximately 30 feet. Batches of parts were periodically delivered to the foaming area by a fork truck. The number of parts and the rate at which they were delivered varied considerably. LEV was in place in the foaming area. The foamer wore shorts and a tee shirt throughout the shift. Chemical goggles and full-length Sol-Vex nitrile gloves (model 37-185) were worn while using the Speedy Packer ${ }^{\mathrm{TM}}$. Respiratory protection was not used. The plant's corporate health and safety department had a written medical surveillance program for workers who worked with isocyanates that provided guidelines for pre-placement and periodic medical evaluations of workers who work with isocyanates. The medical evaluations were to emphasize the respiratory system. Six area samples were collected over the full shift, and two PBZ samples were collected over 15-minute periods to measure peak exposures to MDI and MDI oligomers while the foamer was using the foam-in-bag system. Wipe samples also were obtained for MDI on surfaces in the foaming area. MDI was detected in 4 of 8 air samples at concentrations below applicable exposure criteria. Oligomeric MDI was not detected in any sample. The greatest concentrations, $1.1 \mu \mathrm{g} / \mathrm{m}^{3}$ and $2.3 \mu \mathrm{g} / \mathrm{m}^{3}$, were measured in two short-term PBZ samples collected while the foamer used the foam-in-bag system. Other detectable MDI concentrations were measured near where the bags of foam were placed into boxes and in an area sample collected 10 feet from the foaming operation. The data from this survey indicated that MDI airborne exposures may occur in the foaming area during periodic peak episodes, and that the concentration decreased to non-detectable levels beyond the foaming area, at a distance greater 
than 10 feet from the source. None of the concentrations were near the NIOSH CL of $200 \mu \mathrm{g} / \mathrm{m}^{3}$. Surface wipe tests, conducted immediately after the foam-in-bag system was used, did not identify measurable levels of MDI. As long as the plant was following the corporate written medical surveillance program, NIOSH investigators concluded that an immediate health hazard for persons performing polyurethane foam packaging did not exist at the time of the survey. Recommendations were made for the use of PPE to prevent dermal exposures, and for the establishment of an isocyanate work zone in which only workers medically cleared to work with isocyanates should be permitted.

\section{*HETA 99-0196-2860 August 2001}

Requester: Management

Method(s): Proposed NIOSH 5525 (currently in review) ${ }^{43}$

Range of isocyanates: $5.1 \mu \mathrm{g} / \mathrm{m}^{3}$ and $10.7 \mu \mathrm{g} / \mathrm{m}^{3} \mathrm{HDI}$; $<1.6 \mu \mathrm{g} / \mathrm{m}^{3}$ HDI-based polyisocyanate

Purpose: To evaluate potential exposures to isocyanate containing paints and polyurethane packing foam, and cleaning solvents during cleaning, repairing, and reassembling aircraft parts

Keywords: SIC 3721 (Aircraft and Parts), solvents, naphtha, isocyanates, headache, irritation, polyurethane packing foam, ventilation

* also included in surface coating processes

Abstract: NIOSH evaluated a plant that provided repair and service operations for the airline industry. Health problems identified in the request included headaches and eye irritation, and potential exposures included emissions from isocyanate containing paints and polyurethane packing foam, and cleaning solvents during cleaning, repairing, and reassembling aircraft parts. An initial site visit involved an inspection of the facility, observation of work practices and chemical handling activities, and monitoring petroleum solvent exposures, all of which were below the applicable NIOSH RELs on the day of monitoring.

Then, a follow-up site visit was conducted to measure exposure to isocyanate-containing compounds during the spray-painting and foam packaging operations. Two PBZ exposure measurements were collected from the painter. No HDI monomer was detected, and the HDI-based polyisocyanate exposures were $10.7 \mu \mathrm{g} / \mathrm{m}^{3}$ and $5.1 \mu \mathrm{g} / \mathrm{m}^{3}$. HDI was detected in only one of the seven area air samples collected during spraypainting; a concentration of $0.4 \mu \mathrm{g} / \mathrm{m}^{3}$ was found at the curing oven doors. Also, HDIbased polyisocyanate concentrations were below the MDC of $1.6 \mu \mathrm{g} / \mathrm{m}^{3}$ in the area air samples.

Foam packaging occurred three times during the second site visit. A 10-minute PBZ exposure measurement was collected each time the foam system was used. The foamer's MDI exposures were $3.5 \mu \mathrm{g} / \mathrm{m}^{3}$, $5.2 \mu \mathrm{g} / \mathrm{m}^{3}$, and ND $\left(<2.6 \mu \mathrm{g} / \mathrm{m}^{3}\right)$. MDI-based polyisocyanate was not detected in any sample. Peak exposure was assessed by sampling only when MDI was being dispensed. These sampling times included short samples during each of the three packaging jobs, and a 1-minute period that began when the gun malfunctioned and a small volume of MDI spilled into a box. The results of this sample indicated an average peak exposure of $7.5 \mu \mathrm{g} / \mathrm{m}^{3}$. These exposure concentrations are all well below the NIOSH REL of $200 \mu \mathrm{g} / \mathrm{m}^{3}$ as a 10-minute CL. Neither MDI nor MDIbased polyisocyanates were detected at any of four GA sampling locations near the foam packaging station.

All measured exposures were below applicable NIOSH limits, but several recommendations were provided for improved PPE use (glove use, eye protection, respiratory protection program, hearing conservation program). Also, minimizing skin contact with the polyurethane foam used in the shipping and receiving department was encouraged, and management 
was reminded that engineering controls (e.g., containment, ventilation) or work practice changes (eliminating use of compressed air, depressurization, etc.) should be a first consideration to reduce the potential for exposure.

\section{Foundry Applications}

\section{HETA 98-0237-2872 April 2002}

Requester: Employee

Method(s): Proposed NIOSH 5525 (currently in review $)^{43}$

Range of isocyanates: ND to $0.25 \mu \mathrm{g} / \mathrm{m}^{3}$

MDI

Purpose: To evaluate MDI exposures and respiratory symptoms in the Pepset and No-Bake areas, among other concerns, at an iron foundry

Keywords: SIC 3321 (Gray and Ductile Iron Foundries), cancer, lung disease, respiratory irritation, core making, molding, Stoddard solvent, phenol, ammonia, formaldehyde, cumene, toluene, trimethylbenzene, MDI, HMTA

Abstract: NIOSH conducted an HHE at an iron foundry where workers expressed concern over exposures to formaldehyde, phenol, xylene, isocyanates, toluene, naphthalene, carbon monoxide, trimethyl benzene, cumene, lead, and silica in the Pepset, No- Bake, shell core, green sand, and iron pouring areas; silica and iron dust in the cleaning room, shell core, green sand, and machining areas; oil mist from hydraulic tanks; and asbestos from the concrete plant floors. The HHE request listed respiratory symptoms and possibly increased cancer rates as health concerns.
On March 31-April 1, 1999, NIOSH investigators conducted a walk-through survey, reviewed MSDSs and environmental sampling data, and interviewed 22 workers about the work environment and possible work-related health effects. Employer records were examined to determine the number of cancer cases among workers. On August 8 to 9, 2000, environmental monitoring was conducted for phenol, volatile organic compounds, Stoddard solvent, formaldehyde, toluene, cumene, ammonia, trimethyl benzene isomers, MDI, and HMTA. The five MDI samples collected in the Pepset and NoBake areas ranged from ND to $0.25 \mu \mathrm{g} / \mathrm{m}^{3}$, below occupational exposure limits. Twenty-one (4.4\% of the 475 production workers) were interviewed. Among those interviewed, most workers who had prolonged exposure to emissions from the Pepset and No-Bake coremaking/molding operations reported transient respiratory irritation. The workers who worked in these areas on a regular basis generally did not report persistent respiratory illnesses that they associated with their workplace exposures. Review of the medical records of six workers who reported work-related respiratory illnesses found that some workers had worsening of pre-existing chronic respiratory conditions, although the cause of this was not determined.

Information concerning cancer diagnosed among workers did not reveal an unusual number or pattern of cancers, and it was not possible to determine the cause of the cancers that developed among the workers. Recommendations were provided for additional monitoring for MDI, formaldehyde, and phenol; use of gloves, reporting of health symptoms to medical personnel; and adding LEV in the shell core area. 


\section{Molding}

\section{HETA 89-0198-2133 September 1991}

Requester: Union

Method(s): NIOSH 5521

Range of isocyanates: $<1.1$ to $9.8 \mu \mathrm{g} / \mathrm{m}^{3}$

MDI monomer, 2.0 to $12.2 \mu \mathrm{g} / \mathrm{m}^{3}$ MDI polymer, ND to $253.6 \mu \mathrm{g} / \mathrm{m}^{3}$ NDI

Purpose: To characterize exposures to NDI, MDI, and possible isocyanate-related respiratory problems

Keywords: SIC 3089 (Plastic Products, not elsewhere classified), isocyanate-related asthma, cumulative trauma disorder, carpal tunnel syndrome, thoracic outlet syndrome, MDI, NDI, 2-methoxyethanol

Abstract: NIOSH conducted this HHE to characterize exposures to NDI, MDI, and possible isocyanate-related respiratory problems. Site visits were conducted, and respiratory questionnaires were administered to the workers. NIOSH investigators performed pulmonary function tests and conducted an exposure assessment to determine the workers' exposures to MDI and NDI. In addition, the NIOSH investigators reviewed employee medical records and the OSHA 200 Logs from 1985 to 1989 and conducted a telephone survey of selected workers. The average MDI concentration measured by this sampling was $3.9 \mu \mathrm{g} / \mathrm{m}^{3}$, with concentrations ranging from less than $1.1 \mu \mathrm{g} / \mathrm{m}^{3}$ to $9.8 \mu \mathrm{g} / \mathrm{m}^{3}$.

The average polyisocyanate concentration was $5.6 \mu \mathrm{g} / \mathrm{m}^{3}$, with a range from 2.0 to $12.2 \mu \mathrm{g} / \mathrm{m}^{3}$. Three samples for NDI were ND, three had detectable concentrations but were below the NIOSH REL of $40 \mu \mathrm{g} / \mathrm{m}^{3}$, and one sample was $253.6 \mu \mathrm{g} / \mathrm{m}^{3}$. This high sample was collected within a laboratorytype hood that was used as the mixing station. Smoke tube tests indicated that the hood effectively removed the contaminants from the workers weighing out NDI. About half (7) of the workers previously evaluated for respiratory symptoms had evidence suggestive of NDI-related asthma. Just under half of the workers at the facility who participated in the NIOSH survey reported respiratory symptoms consistent with occupational asthma. On the basis of the data collected during this investigation, NIOSH investigators concluded that a potential health hazard existed from MDI exposure to workers filling the molds and from hot molds exiting the oven. The medical findings further indicate that an isocyanate-related occupational asthma hazard existed at the facility between 1987 and 1988 and that some workers continue to be affected. Investigators provided the standard isocyanate recommendations.

\section{HETA 91-0094 March 1994}

Requester: Management

Method(s): NIOSH 2535 initially, then NIOSH 5522 during 1994 followup

Range of isocyanates: ND for TDI monomer; ND to $37 \mu \mathrm{g} / \mathrm{m}^{3}$ TDI oligomer Purpose: To evaluate TDI and other exposures during the manufacture of polyurethane timing belts for copying machines

Keywords: SIC 2296 (Textile Mill), MDA, TDI, DOP

Abstract: NIOSH conducted this HHE to evaluate TDI and other exposures during the manufacture of polyurethane timing belts by an injection molding process. Initial sampling was performed in April 1991, but because of problems analyzing diisocyanate oligomers at that time, further sampling was delayed until January 1994, subsequent to development of a new analytical method (NIOSH 5522). The 1994 GA air sampling did not detect any TDI monomer $\left(<0.3 \mu \mathrm{g} / \mathrm{m}^{3}\right)$ but measured an average of $19 \mu \mathrm{g} / \mathrm{m}^{3}$ TDI oligomer (range ND to $37 \mu \mathrm{g} / \mathrm{m}^{3}$ ). The highest concentrations were near the main mixing area and the table-top mixing area. However, the GA samples probably overestimated worker exposures since workers spent limited time at these areas. Recommendations were made to add LEV to the mixing areas, and the general isocyanate recommendations were also provided. 


\section{HETA 93-0885}

December 1993

Requester: Government

Method(s): NIOSH 5521 and 5522 (under development)

Range of isocyanates: $\mathrm{ND}$ to $200 \mu \mathrm{g} / \mathrm{m}^{3} \mathrm{MDI}$

Purpose: To evaluate potential occupational health problems from exposure to MDI during hot tub manufacture

Keywords: SIC 3088 (Plastics Plumbing

Fixtures) hot tub, isocyanates, MDI, air sampling

Abstract: NIOSH conducted this HHE at a hot tub manufacturing company to evaluate potential occupational health problems from exposure to MDI. Most of the air concentrations were near the NIOSH REL of $50 \mu \mathrm{g} / \mathrm{m}^{3}$ but only as a TWA for 30 to 45 minutes. When averaged over 10 hours, the effective TWA is well below the REL. One of the air samples was equal to the NIOSH, OSHA, and ACGIH CL of $200 \mu \mathrm{g} / \mathrm{m}^{3}$. Investigators provided the standard isocyanate recommendations, as well as one for posting signs that warn of the danger of exposure to diisocyanates at the entrance to the spray area.

\section{HETA 94-0072-2648 August 1997}

Requester: Union

Method(s): NIOSH 5522

Range of isocyanates: ND

Purpose: To determine isocyanate exposures during a liquid composite molding process, as well as other exposures in other areas of the facility

Keywords: SIC 3061 (Molded, extruded, lathe cut Mechanical rubber goods) rubber, rubber vehicle sealing, sheet molding compound, liquid composite molding, nitrosamines, nitrosodimethylamine, NDMA, nitrosopiperidine, NPIP, nitrosomorpholine, NMOR, nitosodiethylamine, NDEA, nitosodibutylamine, NDBA, nitrosodipropylamine, NDPA, nitrosopyrrolidine, NPYR, DNA Adducts, $\mathrm{N}^{7}$ methyldeoxyguanosine, $\mathrm{O}^{6}$ methyldeoxyguanosine, $\mathrm{O}^{6}$ alkylguanineDNA alkyltransferase, AGT, VOCs, isocyanates, MDI

Abstract: NIOSH conducted this HHE to determine health hazards in a facility that manufactured automotive parts, including rubber vehicle sealing, sheet molding compound, and liquid composite bumper beams. During the liquid composite molding process, a two-component polyurethane coating system was injected into the mold.

Component $\mathrm{A}$ was MDI monomer and polyisocyanate, and component B was a polyol/glycol blend. GA samples did not detect any measurable MDI, and it was concluded that the LEV was effectively controlling emissions. 


\section{HETA 97-0138-2677 February 1998}

Requester: Management Method(s): NIOSH 5522

Range of isocyanates: ND to $130 \mu \mathrm{g} / \mathrm{m}^{3}$ MDI; ND to $320 \mu \mathrm{g} / \mathrm{m}^{3}$ MDI oligomer Purpose: To identify and control headache and nausea-causing chemicals during pours of bronze castings

Keywords: SIC 3366 (Castings, except die-castings: brass, bronze, copper, and copper-base alloy), foundry, phenol, MDI

Abstract: NIOSH conducted an HHE at this bronze-casting facility to help identify and control headache and nausea-causing chemicals during pours of bronze castings. The company identified the sand mold resin bonding system as the suspected source of the irritating chemicals. Air sampling was conducted for MDI and other suspected exposures, including aldehydes, phenol, and VOCs. Only one MDI sample was above the analytical LOD ( $3 \mu \mathrm{g} /$ sample). The airborne concentration measured by that sample was $130 \mu \mathrm{g} / \mathrm{m}^{3}$ over a 32-minute period, which is below the NIOSH REL as a ceiling of $200 \mu \mathrm{g} / \mathrm{m}^{3}$. One oligomer sample was detectable and equated to an air concentration of $320 \mu \mathrm{g} / \mathrm{m}^{3}$ for a 19-minute sample. Recommendations for exhaust ventilation and PPE were provided to reduce exposures to other chemicals at the work site.

\section{Surface Coating}

\section{HETA 89-0010 January 1990}

Requester: Management Method(s): NIOSH 5521 with modifications Range of isocyanates: 4.9 to $113.9 \mu \mathrm{g} / \mathrm{m}^{3}$ TDI Purpose: To investigate potential exposure to isocyanates in floor coatings Keywords: SIC 1752 (Floor Laying and Other Floor Work, not elsewhere classified), isocyanates, formaldehyde, wood dust

Abstract: NIOSH was requested to conduct an HHE to evaluate exposures during floor refinishing operations. NIOSH conducted air sampling for isocyanates during floor refinishing operations that used a urethane finish. PBZ concentrations of TDI ranged from $4.9 \mu \mathrm{g} / \mathrm{m}^{3}$ to $113.9 \mu \mathrm{g} / \mathrm{m}^{3}$. GA samples ranged from 14.2 to $85.4 \mu \mathrm{g} / \mathrm{m}^{3}$. NIOSH investigators provided the standard isocyanate recommendations, as well as recommendations to reduce other exposures

\section{HETA 89-0071 May 1990}

Requester: Employee

Method(s): NIOSH 5521

Range of isocyanates: ND for MDI monomer, semi-quantitative results of $\mathrm{ND}$ to $55 \mu \mathrm{g} / \mathrm{m}^{3}$ MDI equivalents (prepolymers)

Purpose: To evaluate exposures to isocyanates and VOCs potentially released when removing and applying an encapsulant used to protect telephone cable splices Keywords: SIC 1731 (Electrical Work) diisocyanates, VOCs, polyurethane encapsulants

Abstract: NIOSH conducted this HHE to evaluate exposures to isocyanates and VOCs potentially released when removing and applying an encapsulant used to protect telephone cable splices. Workers reported symptoms of raspy voice, shortness of breath, and headaches. NIOSH had 
conducted two previous HHEs related to polyurethane encapsulants in underground cable vaults and had not documented any isocyanate exposures. Similarly, no MDI was detected during this survey. However, the laboratory provided semi-quantitative results for MDI oligomers, reported as the equivalent amount of MDI monomer that could supply the same concentration of reactive isocyanate groups. These concentrations ranged from ND to $55 \mu \mathrm{g} / \mathrm{m}^{3} \mathrm{MDI}$ equivalents. Investigators hypothesized that the residual MDI monomer in the encapsulant activator is not released because it quickly reacts with the polyol during mixing.

Recommendations were made for respiratory protection for individuals who experience irritation and for hazard communication.

\section{HETA 89-0276-2093 January 1991}

Requester: Union

Method(s): NIOSH 5521

Range of isocyanates: 14 to $34 \mu \mathrm{g} / \mathrm{m}^{3} \mathrm{HDI}$

Purpose: To evaluate exposures to epoxy and polyurethane paints being sprayed in open areas on an aircraft assembly line

Keywords: SIC 3721 (Aircraft Manufacture) paint, solvents, organic vapor, trace metals, HDI, isocyanates

Abstract: NIOSH conducted this HHE to evaluate exposures to epoxy and polyurethane paints being sprayed in open areas on an aircraft assembly line. Some of the assembly line workers had reported breathing difficulties and respiratory problems. Sampling for HDI monomer and oligomers detected concentrations of 14 to $34 \mathrm{\mu g} / \mathrm{m}^{3}$, just above the analytical LOD Investigators concluded that there was a minimal risk of HDI exposure to nonpainters but did recommend that open spraying practices be limited to times when the building is mostly unoccupied or that spraying operations be controlled by LEV. They also provided standard isocyanate recommendations.

\section{HETA 90-0368-2137 September 1991}

Requester: Management Method(s): NIOSH 5521

Range of isocyanates: ND for HDI monomer, $<3.6$ to $162.6 \mu \mathrm{g} / \mathrm{m}^{3}$ HDI oligomer Purpose: To investigate possible employee exposures to paint solvents and aerosols Keywords: SIC 3714 (Motor Vehicle Parts and Accessories), axle housings and shafts, HDI, isocyanates, diisocyanates, MIK, MEK, xylene, chromium, cobalt, polyurethane paint, epoxy paint

Abstract: NIOSH conducted this HHE in the axle painting area of this motor vehicle parts manufacturing facility to investigate possible employee exposures to paint solvents and aerosols. Full-shift PBZ monitoring for solvent vapors and $\mathrm{GA}$ air monitoring for metals and diisocyanates were conducted throughout the axle painting line. The paint booth systems were observed, employee interviews were conducted, and health symptom questionnaires were distributed to the affected workers. Area sampling for HDI showed concentrations above the NIOSH REL TWA criteria of $35 \mu \mathrm{g} / \mathrm{m}^{3}$ in the paint kitchen, near the hook touch-up painter (who used a spray bottle), behind a paint robot, and at the exit to a touch-up booth. One measurement behind the paint robot $\left(162.6 \mu \mathrm{g} / \mathrm{m}^{3}\right.$ HDI oligomer) was above the NIOSH STEL of $140 \mu \mathrm{g} / \mathrm{m}^{3}$. Respirators were not being used in these areas. Because of a problem with high field blank values, a photodiode array ultraviolet detector was used to corroborate HDI oligomer data. Ten workers were either interviewed or completed questionnaires regarding possible health symptoms in the axle painting area. Several of the workers reported sinus and respiratory symptoms, dizziness, and drowsiness. Of the four workers who reported sinus or respiratory problems, three indicated that they had allergies or often had sinus problems when not at the plant. One employee reported headaches while at work, and one reported occasionally feeling 
"flush to the face." This investigation identified a potential health hazard from exposure to HDI in specific areas of the axle painting area. Investigators provided standard isocyanate recommendations and ones for improving engineering controls and work practices.

\section{HETA 93-0842 February 1995}

Requester: Employee

Method(s): NA

Range of isocyanates: NA

Purpose: To investigate the occurrence of occupational asthma in workers exposed to diisocyanates during the spray painting of vehicles

Keywords: SIC 4911 (Electric Services), electric utilities, vehicle repair, diisocyanates, styrene, liver function tests, HDI

Abstract: NIOSH conducted this HHE to investigate the occurrence of occupational asthma in workers exposed to diisocyanates during the spray painting of vehicles. An initial medical investigation resulted in the following recommendations: that workers potentially exposed to diisocyanates should receive annual medical examinations (including spirometry); that workers handling liquid chemicals wear gloves, protective clothing, and safety goggles; and that all workers receive hazardous communication training. A follow-up survey by an industrial hygienist was conducted to observe the spray-painting operations. On the basis of the observations made during the $\mathrm{NIOSH}$ site visit and the existing data in the scientific literature on these exposures and processes, the NIOSH investigators did not believe that any further evaluation was necessary. The combination of the sidedraft painting booth, supplied-air respiratory protection, and PPE were deemed adequate measures for protecting workers from hazardous exposure to the diisocyanates (HDI monomer and prepolymers) and other chemicals found in the paints. The NIOSH investigators recommended that the mixing of the polyurethane paint be moved from the work bench to the side-draft painting booth to control any diisocyanate vapors that could emanate during this task and to prevent secondary exposure to nearby workers.

\section{HETA 95-0065 August 1995}

Requester: Union

Method(s): OSHA 42 by an independent consultant prior to the HHE

Range of isocyanates: 0.05 to $0.2 \mu \mathrm{g} / \mathrm{m}^{3} \mathrm{MDI}$ Purpose: To determine whether employee health problems could be related to a floor-tile encapsulation process

Keywords: SIC 4311 (Postal Service), isocyanates, diisocyanates, MDI, respiratory disease

Abstract: NIOSH conducted this HHE to investigate employee complaints of health problems (respiratory problems, abdominal pains, vomiting, heart attacks, skin rashes and hair loss) possibly related to chemical encapsulation of floor-tile the prior year. NIOSH reviewed background information about the health complaints and the chemicals used in the encapsulation process. Prior to the HHE, an independent consultant conducted air monitoring near the encapsulation area to estimate exposures to monomeric MDI. Area air concentrations ranged from 0.05 to $0.2 \mu \mathrm{g} / \mathrm{m}^{3}$, expressed as 8-hour TWAs. The NIOSH REL is $50 \mu \mathrm{g} / \mathrm{m}^{3}$ as a 10 -hour TWA and $200 \mu \mathrm{g} / \mathrm{m}^{3}$ as a CL. A review of the data by NIOSH investigators revealed that the sampling was performed on a day when a sealer that did not contain MDI was being used. Investigators also pointed out that the OSHA 42 method can underestimate MDI monomer exposures and does not measure oligomeric MDI or phenyl isocyanate, which were also present in the encapsulants. NIOSH investigators concluded that during the encapsulation project, exposures to monomeric and oligomeric isocyanates could potentially have caused chemical induced mucosal irritation and or respiratory symptoms among some workers. 


\section{HETA 95-031 1-2593 August 1996}

Requester: Management

Method(s): NIOSH 5522.1

Range of isocyanates: ND for HDI monomer, ND to $482 \mu \mathrm{g} / \mathrm{m}^{3}$ for HDI oligomer

Purpose: To assess worker exposures to isocyanates during spray painting of automobiles

Keywords: SIC 7532 (Top, Body, and Upholstery Repair Shops and Paint Shops), isocyanates, solvents, total dust, carbon monoxide, noise, respirators, HDI

Abstract: NIOSH conducted an HHE at this autobody repair shop to help assess worker exposure to isocyanates during spray painting of automobiles. Two site visits were conducted several months apart to assess effects of seasonal variation. Activities in the repair shop included fume straightening, panel repair/replacement body filling, and final painting and detailing. Workers used isocyanate-catalyzed paints composed of a base coat, a reducer, and a hardener. The paints contained HDI polymer and very small amounts of the monomer $(<0.006 \%)$. Some of the hardeners also contained IPDI polymer and monomer. PBZ (collected by attaching the impingers to workers' belts) and GA airborne levels of isocyanate (HDI only) monomer and oligomers were measured. All of the oligomer and most of the monomer samples collected during the first visit were below the analytical LOD of $2 \mu \mathrm{g}$ per sample. One area sample collected within the spray booth found a trace amount of the oligomer. One personal sample collected on the head painter at the end of the day when he was applying clear coat paint measured $99 \mu \mathrm{g} / \mathrm{m}^{3}$, which is above the NIOSH REL of $35 \mu \mathrm{g} / \mathrm{m}^{3}$ for an 8-hour TWA but below the $140 \mu \mathrm{g} / \mathrm{m}^{3}$ ceiling REL. The head painter's TWA for the day was $29 \mu \mathrm{g} / \mathrm{m}^{3}$. The samples from the second visit showed all monomer exposures as below the analytical LOD; most oligomer samples had detectable results. These ranged from 83 to $482 \mu \mathrm{g} / \mathrm{m}^{3}$. Although isocyanate exposures were below the various evaluation criteria, NIOSH recommends air-supplied respirators whenever there is the potential for exposure to isocyanates, and thus, all the standard isocyanate recommendations were provided.

\section{HETA 95-0405-2600 September 1996}

Requester: Management

Method(s): NIOSH 5522

Range of isocyanates: ND to $750 \mu \mathrm{g} / \mathrm{m}^{3} \mathrm{HDI}$ monomer, ND to $667 \mu \mathrm{g} / \mathrm{m}^{3} \mathrm{HDI}$ oligomer Purpose: To assess worker exposure to isocyanates during spray painting of automobiles

Keywords: SIC 7532 (Top, Body, and Upholstery Repair Shops and Paint Shops), isocyanates, solvents, total dust, carbon monoxide, noise, respirators, HDI

Abstract: NIOSH conducted an HHE at this autobody repair shop to help assess worker exposure to isocyanates during spray painting of automobiles. Two site visits were conducted several months apart to assess effects of seasonal variation.

Activities in the shop included frame straightening panel repair/replacement, body filling, painting, and detailing. Workers used isocyanate-catalyzed paints containing HDI polymer and very small amounts of the monomer $(>0.006 \%)$. Some of the hardeners also contained isophorone diisocyanate polymer and monomer. PBZ (collected by attaching the impingers to workers' belts) and GA airborne concentrations of isocyanate (HDI only) monomer and oligomers were measured. All but one of the monomer samples collected in both time periods were below the analytical LOD of $2 \mu \mathrm{g}$ per sample. One personal sample for HDI monomer collected was $750 \mu \mathrm{g} / \mathrm{m}^{3}$ for an 8-minute sample, which is in excess of the NIOSH ceiling REL of $140 \mu \mathrm{g} / \mathrm{m}^{3}$. The oligomer samples from both time periods ranged from below the LOD $(2 \mu \mathrm{g}$ per sample) to $667 \mu \mathrm{g} / \mathrm{m}^{3}$ (TWA concentrations for the two painters ranged from 38 to $65 \mu \mathrm{g} / \mathrm{m}^{3}$ ). The TWA concentrations were below the industry recommended 
TWA of $500 \mu \mathrm{g} / \mathrm{m}^{3}$. Although isocyanate exposures were below the various evaluation criteria, NIOSH recommends air-supplied respirators whenever there is the potential for exposure to isocyanates, and thus, all the standard isocyanate recommendations were provided.

\section{HETA 95-0406-2609 October 1996}

Requester: Management

Method(s): NIOSH 5522

Range of isocyanates: $\mathrm{ND}$ to $40 \mu \mathrm{g} / \mathrm{m}^{3} \mathrm{HDI}$ monomer, ND to $>500 \mu \mathrm{g} / \mathrm{m}^{3} \mathrm{HDI}$ oligomer Purpose: To assess worker exposure to isocyanates during spray painting of automobiles

Keywords: SIC 7532 (Top, Body, and Upholstery Repair Shops and Paint Shops), isocyanates, solvents, total dust, carbon monoxide, noise, respirators, HDI

Abstract: NIOSH conducted this HHE to assess worker exposure to isocyanates and other hazards during spray painting of automobiles. Two site visits were conducted several months apart to assess effects of seasonal variation. Measurements included PBZ (collected by attaching the impingers to workers' belts) and GA airborne levels of HDI monomer and oligomers. All HDI monomer samples were below the analytical limit of detection ( 3 to $5 \mu \mathrm{g} /$ sample), except one. This was an area sample at $40 \mathrm{\mu g} / \mathrm{m}^{3}$, collected in the paint booth for 4 hours. The 8-hour TWA exposure in the booth was below the NIOSH REL of $35 \mu \mathrm{g} / \mathrm{m}^{3}$. The oligomer samples from the first visit ranged from below the LOD (3 $\mathrm{\mu g} / \mathrm{sample}$ ) up to $261 \mu \mathrm{g} / \mathrm{m}^{3}$. PBZ oligomer samples collected during the second visit were higher, often, if briefly, exceeding the industry recommendation of $500 \mu \mathrm{g} / \mathrm{m}^{3}$. However, when time-weighed over the full shift, all exposures were below $500 \mu \mathrm{g} / \mathrm{m}^{3}$. Although HDI monomer exposures were below the various evaluation criteria, NIOSH recommends air-supplied respirators whenever there is the potential for exposure to isocyanates, and thus all the standard isocyanate recommendations were provided.

\section{HETA 96-0266-2702 August 1998}

Requester: Management

Method(s): NIOSH 5522

Range of isocyanates: $<1.6 \mu \mathrm{g} / \mathrm{m}^{3}$ (below the MDC)

Purpose: To evaluate workers' exposure to isocyanates from a two-component, waterbased polyurethane paint

Keywords: SIC 3061 (Molded, Extruded, and Lathe-Cut Mechanical Rubber Goods), vehicle sealing, automotive/truck rubber seals, water-based polyurethane paint, polyfunctional aziridine, N-methyl pyrrolidone, isocyanates, skin patch testing, allergic contact dermatitis

Abstract: NIOSH conducted this HHE to evaluate workers' exposure from a twocomponent, water-based polyurethane paint (water-based polyurethane paint with polytetrafluoroethylene and a polyfunctional aziridine cross-linker) that was applied to automotive truck rubber seals (vehicle sealing) on the dual durometer extrusion lines. Health effects described in the request included skin and upper respiratory problems. NIOSH investigators conducted a site visit during which they administered a questionnaire, performed skin patch testing, and collected air samples for nitrosamines, VOCs, and isocyanates at various locations on the extrusion lines. All isocyanate concentrations were below the MDC of $1.6 \mu \mathrm{g} / \mathrm{m}^{3}$. Although isocyanate exposures were below NIOSH REL, recommendations were provided to reduce exposure to other workplace hazards. 


\section{*HETA 97-0084-2669 December 1997}

Requester: Management

Method(s): NIOSH 5522

Range of isocyanates: Spray painting5.1 to $9.6 \mu \mathrm{g} / \mathrm{m}^{3}$ 2,4-TDI monomer, 7.4 to $17.9 \mu \mathrm{g}-\mathrm{NCO} / \mathrm{m}^{3}$ TRIGs, ND 2,6-TDI monomer; packaging-ND MDI monmer, ND to $15.5 \mu \mathrm{g} / \mathrm{m}^{3}$ MDI oligomer, $<9.8 \mu \mathrm{g}-\mathrm{NCO} / \mathrm{m}^{3}$ TRIGs

Purpose: To document worker exposure to isocyanates during spray painting and packaging processes

Keywords: SIC 3519 (Internal Combustion Engines, not elsewhere classified), noise, isocyanates, metal working fluids, TDI and MDI, TRIG, toluene, xylene, formaldehyde, inorganic acids, ammonia, lead

* also included in surface coating processes

Abstract: NIOSH conducted this HHE to document worker exposure to isocyanates during spray painting and packaging of engine control devices. Monitoring for TDI and MDI monomers and oligomers and TRIGs was conducted. Area air sampling results for TDI during spray painting operations ranged from 5.1 to 9.6 for 2,4-TDI monomer, and from 7.4 to $17.9 \mu \mathrm{g} \mathrm{NCO} / \mathrm{m}^{3}$ for TRIGs. No 2,6-TDI monomer was detected. These data indicate that area isocyanate levels are low for spray painting operations, especially when compared to the ACGIH TLV for TDI (8-hour TWA of $36 \mu \mathrm{g} / \mathrm{m}^{3}$ ) and the UK-HSE standard for TRIG (8-hour TWA $20 \mu \mathrm{g} \mathrm{NCO} / \mathrm{m}^{3}$ ). The low levels indicated that the spray booth was effectively containing the isocyanates. Area air samples collected for MDI during packaging operations did not detect MDI monomer but detected oligomer concentrations ranging from ND to $15.5 \mu \mathrm{g} / \mathrm{m}^{3}$. The TRIG concentrations were all below $9.8 \mu \mathrm{g} \mathrm{NCO} / \mathrm{m}^{3}$. Although MDI concentrations were low, the design of the local exhaust systems for the packaging needed improvements. NIOSH provided the standard isocyanate recommendations.

\section{HETA 97-0157 October 1997}

Requester: Employee originally, but then a TA to the U.S. Coast Guard Method(s): OSHA 42, performed by a consultant prior to the HHE Range of isocyanates: ND (HDI)

Purpose: To characterize employee health effects, including throat pain, coughing at night, chest tightness and gastrointestinal problems, from isocyanate-containing paints used to paint barges Keywords: SIC 4449 (Water Transport of Freight), HDI

Abstract: NIOSH provided TA to the U.S. Coast Guard to characterize employee health effects from isocyanate-containing paints used to paint barges. Workers at the site complained of throat pain, coughing at night, chest tightness, and gastrointestinal problems possibly associated with isocyanate painting operations. Investigators reviewed painting procedures, products, PPE, and hazard communication and medical management policies. In addition, investigators reviewed employee medical records and interviewed workers. It was apparent that the company had enacted policies in an effort to reduce worker paint exposures, such as the implementation of PPE, the restriction of spray painting, and education in health hazards. Air monitoring done previous to the HHE by an independent consultant did not detect any HDI, but the method used was OSHA 42 and a real-time monitor that are only for HDI monomers, not the HDI polyisocyantes in the barge paints. The Coast Guard closed the investigation with the standard isocyanate recommendations, which would have been necessary with or without additional air sampling. 


\section{HETA 97-0226}

\section{December 1998}

Requester: Employee

Method(s): NIOSH 5522

Range of isocyanates: ND (MDI)

Purpose: To investigate the occurrence of isocyanate-induced asthma in an employee and to evaluate potential exposures to solvent-containing and dust-producing materials in a woodworking facility Keywords: SIC 3999 (Manufacturing Industries, not elsewhere classified), manufacturing, asthma HP, isocyanate, polyurethane, solvents, dust

Abstract: NIOSH conducted an HHE at this woodworking facility to investigate the occurrence of isocyanate-induced asthma in an employee and to evaluate potential exposures to solvent-containing and dustproducing materials. Investigators conducted a site visit, met with management and employee representatives, and reviewed medical records of the symptomatic employee. PBZ and area air samples were taken for isocyanates, solvents, and dust. While the symptomatic worker was shown to have airflow obstruction and a clinical picture suggestive of isocyanate-related asthma, of additional concern was the abnormality in diffusing capacity test results implying a disorder other than asthma. In situations involving exposure to isocyanates, these results could represent interstitial lung disease or HP. Air sampling did not indicate overexposure to any of the air contaminants measured. It should be noted that there have been cases of isocyanate sensitization where sampling measured only minimal concentrations. The standard isocyanate exposure recommendations were provided as well as these specific ones: parts to be sprayed in the spray room should be positioned to avoid overspray that can cause vapor to travel toward the worker's breathing zone; the resin casting bench should be repositioned in the room to avoid this same problem for the casting worker as well as the spraying worker (since he is downstream of the casting operation), and the addition of LEV should be considered for the task of sanding wooden mounts.

\section{HETA 98-0073 March 2000}

Requester: Union

Method(s): None reported (reviewed company sampling results)

Range of isocyanates: $<1.4 \mu \mathrm{g} / \mathrm{m}^{3}$ to $.062 \mu \mathrm{g} / \mathrm{m}^{3} \mathrm{HDI}$

Purpose: To evaluate, among other things, the exposure to HDI during the manufacture of tape with an acrylate and polyurethane coating

Keywords: SIC 3083 (Laminated Plastic Plate Sheet, and Profile Shapes), tape, laminated tape, dimethyl acrylamide, hexandiol, diacrylate, isooctyl acrylate, HDI, isocyanates, dermatitis, respiratory symptoms

Abstract: At the request of the local union, NIOSH conducted a walk-through survey and reviewed IH sampling results and medical records at a plant that produced various tapes. The union said that workers were experiencing respiratory, dermal, and nervous system health effects that might be related to the various cleaners, adhesives, and tape coatings used in the tape making departments. The HDI exposures $\left(<1.4 \mu \mathrm{g} / \mathrm{m}^{3}\right.$ to $\left.0.62 \mu \mathrm{g} / \mathrm{m}^{3}\right)$ were only on one line and were well below the NIOSH REL of $35 \mu \mathrm{g} / \mathrm{m}^{3}$. No sampling was done for HDI-based polyisocyante. Most other sampling results from the department were low, except for an overexposure to dimethyl acrylamide in the Mill/Mix area from improper use of the LEV. The lower respiratory symptoms and skin irritation were consistent with exposure to many of the chemicals in the department, including HDI. Employee and company nurse interviews, as well as review of medical records, indicated that workers who had experienced potentially work-related health effects were being appropriately referred for medical follow-up. Also, workers diagnosed with workrelated symptoms by the occupational medicine consultant were appropriately 
reassigned. Skin protection was inadequate in some cases, most importantly with one employee handling the isocyanate solution. Many of the chemicals in the department could cause dermal sensitization, but investigators pointed out that dermal contact with isocyanates has been shown to cause respiratory sensitization in animals, further emphasizing the need for adequate skin protection. Recommendations were provided for continued development and appropriate use of engineering controls, use of appropriate PPE, proper hygiene practices, improved hazard education, medical surveillance, and further IH monitoring, especially for HDI-based polyisocyanate.

\section{HETA 98-0347-2758 November 1999}

Requester: Joint employee and management Method(s): NA

Range of isocyanates: NA

Purpose: To investigate office workers' exposures to diisocyanate-containing paints, primers, solvents, and cured and uncured composite materials used during the manufacture of fighter jets in the production area below the office

Keywords: SIC 381 (Search, Detection, Navigation, Guidance, Aeronautical, and Nautical Systems, Instruments, and Equipment) IEQ, IAQ, ventilation, tracer gas, sulfur hexafluoride, composites, diisocyanate-containing paints, MEK, MIBK, isopropanol, occupational asthma, chemical sensitization, mucous membrane irritation

Abstract: NIOSH conducted an HHE at a manufacturer of fighter jets to investigate office workers' exposures to diisocyanatecontaining paints, primers, solvents, and cured and uncured composite materials used in the production area below the office. Employee interviews revealed that approximately $88 \%$ of the workers $(14 / 16)$ reported symptoms, which included eye, nose, and throat irritation, cough, wheezing, shortness of breath, chest pain, headache, nausea, dizziness, fatigue, numbness / tingling of the extremities, and skin rashes.
Thirteen of the fourteen symptomatic workers reported that symptoms diminished when away from work, and nine of the thirteen were diagnosed by a pulmonary specialist with a variety of respiratory conditions attributable to chemical exposures in the work place. The symptoms were consistent with exposures to isocyanates and irritative solvents that were used in the production area. NIOSH conducted a tracer gas study to evaluate the effectiveness of newly implemented engineering controls and concluded that the changes had successfully controlled emissions from the paint spray booth and core-clean room, but that exposures generated near the AHU in the production area could potentially reach office workers. Investigators provided recommendations to address the IEQ concerns, including ventilation changes, hazard communication, and production area/office area/management communication.

\section{HETA 99-0122-2798 June 2000}

Requester: Management

Method(s): Proposed NIOSH 5525 (currently in review $)^{43}$

Range of isocyanates: $300 \mu \mathrm{g} / \mathrm{m}^{3}$ to $1364 \mu \mathrm{g} / \mathrm{m}^{3} \mathrm{MDI} ; 304 \mu \mathrm{g} / \mathrm{m}^{3}$ to $1080 \mu \mathrm{g} / \mathrm{m}^{3}$ MDI-based polyisocyanate; $1.9 \mu \mathrm{g} / \mathrm{m}^{3} \mathrm{HDI}$; $164 \mu \mathrm{g} / \mathrm{m}^{3}$ HDI-based polyisocyanate; and $83 \mu \mathrm{g}-\mathrm{NCO} / \mathrm{m}^{3}$ to $831 \mu \mathrm{g}-\mathrm{NCO} / \mathrm{m}^{3}$ TRIG Purpose: To evaluate worker exposures to isocyanate-containing compounds during spray-painting operations at a plant that manufactured military aircraft

Keywords: SIC 3721 (Aircraft), spray painting, polyurethane surface coating, isocyanates, $\mathrm{HDI}, \mathrm{MDI}$, polyisocyanates

Abstract: NIOSH received a management request to assess worker exposures to isocyanate-containing compounds during spray painting operations at a plant that manufactured military aircraft. On February 17 to 18, 1999, investigators from NIOSH conducted a site visit and exposure assessment for these compounds. Air 
sampling was conducted during polyurethane spray painting operations in two paint booths (219 and L-64). Two different isocyanate-containing polyurethane paints were used in these spray painting operations. Both paints were two-component formulations, and were identified by the in-house designations of code 36 and code 46 . The code 36 paint contained $40 \%$ by weight HDI-based polyisocyanate, and less than $0.15 \%$ HDI. The code 46 paint contained $40 \%$ by weight of MDI, and 50\% MDI-based polyisocyanate. During spray painting, the painters wore a full-face air-purifying respirator with combined particulate and organic vapor cartridges, and a Tyve ${ }^{\mathrm{TM}}$ suit. PBZ and area air sampling were collected to determine short-term, taskbased exposures and general airborne concentrations to the isocyanate-containing compounds found in the paints. All area air samples were collected using midget impingers containing 15-ml of MAP in butyl benzoate, followed by a 37-mm diameter QFF impregnated with MAP. PBZ air samples were collected using the MAP-impregnated QFFs. Filter samples were analyzed by HPLC with ultraviolet and fluorescence detection for both the monomer and polyisocyanate components of the paints. The impinger samples underwent solid-phase extraction, followed by the same analysis used for the filter samples. Monomers were quantified based on comparison of their fluorescence peak heights to those of monomer standards. If detected, polyisocyanates/oligomers were quantified based on the comparison of their ultraviolet peak areas to those of monomer standards.

At the time of the NIOSH survey, two painters were painting parts in booth 219. The painter on the right side of the booth used the code 46 paint, the painter on the left side used the code 36 paint. The MDI and MDI-based polyisocyanate exposure concentrations were $300 \mu \mathrm{g} / \mathrm{m}^{3}$ and $304 \mathrm{\mu g} / \mathrm{m}^{3}$ for the right side (code 46) painter, respectively. For the left side (code 36) painter, the HDI and HDI-based polyisocyanate exposures were $1.9 \mu \mathrm{g} / \mathrm{m}^{3}$ and $164 \mu \mathrm{g} / \mathrm{m}^{3}$, respectively. Only one painter worked in the L-64 booth. This painter used the code 46 paint, and the MDI exposure was $1364 \mu \mathrm{g} / \mathrm{m}^{3}$ and the MDI-based polyisocyanate exposure was $1080 \mu \mathrm{g} / \mathrm{m}^{3}$. In addition, the TRIG exposures for painters in booth 219 were $206 \mu \mathrm{g}-\mathrm{NCO} / \mathrm{m}^{3}$ and $83 \mu \mathrm{g}-\mathrm{NCO} / \mathrm{m}^{3}$, and the TRIG exposure for the L-64 painter was $831 \mu \mathrm{g}-\mathrm{NCO} / \mathrm{m}^{3}$. Finally, significant airborne concentrations of the various isocyanate-containing compounds were found by the area air sampling conducted in both spray-painting booths. Considering the MDI, MDI-based polyisocyanate, HDI-based polyisocyanate, and TRIG exposure concentrations, the NIOSH investigators concluded that a health hazard existed in the spray-painting booths/operations evaluated during this study. Recommendations were provided to increase the level of protection for workers in the spray-painting operations that included respiratory protection, protective clothing, medical surveillance, and IH surveillance.

\section{*HETA 99-0196-2860 August 2001}

Requester: Management

Method(s): Proposed NIOSH 5525 (currently in review $)^{43}$

Range of isocyanates: $5.1 \mu \mathrm{g} / \mathrm{m}^{3}$ and $10.7 \mu \mathrm{g} / \mathrm{m}^{3} \mathrm{HDI}$; $<1.6 \mu \mathrm{g} / \mathrm{m}^{3}$ HDI-based polyisocyanate

Purpose: To evaluate potential exposures to isocyanate containing paints and polyurethane packing foam, and cleaning solvents during cleaning, repairing, and reassembling aircraft parts

Keywords: SIC 3721 (Aircraft and Parts), solvents, naphtha, isocyanates, headache, irritation, polyurethane packing foam, ventilation

* also included in foaming processes

Abstract: NIOSH evaluated a plant that provided repair and service operations for the airline industry. Health problems identified in the request included headaches and eye irritation, and potential exposures included emissions from iso- 
cyanate containing paints and polyurethane packing foam, and cleaning solvents during cleaning, repairing, and reassembling aircraft parts. An initial site visit involved an inspection of the facility, observation of work practices and chemical handling activities, and monitoring petroleum solvent exposures, all of which were below the applicable NIOSH RELs on the day of monitoring.

Then, a follow-up site visit was conducted to measure exposure to isocyanate-containing compounds during the spray-painting and foam packaging operations. Two PBZ exposure measurements were collected from the painter. No HDI monomer was detected, and the HDI-based polyisocyanate exposures were $10.7 \mu \mathrm{g} / \mathrm{m}^{3}$ and $5.1 \mu \mathrm{g} / \mathrm{m}^{3}$. HDI was detected in only one of the seven area air samples collected during spray painting; a concentration of $0.4 \mu \mathrm{g} / \mathrm{m}^{3}$ was found at the curing oven doors. Also, HDIbased polyisocyanate concentrations were below the MDC of $1.6 \mu \mathrm{g} / \mathrm{m}^{3}$ in the area air samples.

Foam packaging occurred three times during the second site visit. A 10-minute PBZ exposure measurement was collected each time the foam system was used. The foamer's MDI exposures were $3.5 \mu \mathrm{g} / \mathrm{m}^{3}$, $5.2 \mu \mathrm{g} / \mathrm{m}^{3}$, and ND $\left(<2.6 \mu \mathrm{g} / \mathrm{m}^{3}\right)$. MDI-based polyisocyanate was not detected in any sample. Peak exposure was assessed by sampling only when MDI was being dispensed. These sampling times included short samples during each of the three packaging jobs, and a 1-minute period that began when the gun malfunctioned and a small volume of MDI spilled into a box. The results of this sample indicated an average peak exposure of $7.5 \mu \mathrm{g} / \mathrm{m}^{3}$. These exposure concentrations are all well below the NIOSH REL of $200 \mu \mathrm{g} / \mathrm{m}^{3}$ as a 10-minute CL. Neither MDI nor MDI-based polyisocyanates were detected at any of four GA sampling locations near the foam packaging station.

All measured exposures were below applicable NIOSH limits, but several recommendations were provided for improved PPE use (glove use, eye protection, respiratory protection program, hearing conservation program). Also, minimizing skin contact with the polyurethane foam used in the shipping and receiving department was encouraged, and management was reminded that engineering controls (e.g., containment, ventilation) or work practice changes (eliminating use of compressed air, depressurization, etc.) should be a first consideration to reduce the potential for exposure.

\section{Other}

\section{HETA 89-083-2134 September 1991}

Requester: Employee

Method(s): Not reported

Range of isocyanates: ND for MDI, 39 to

$53 \mu \mathrm{g} / \mathrm{m}^{3} \mathrm{PPI}$, ND to trace $2,4 \mathrm{TDI}$, and ND

for 2,6-TDI

Purpose: To investigate respiratory complaints (including asthma) at a plastics manufacturer

Keywords: SIC 3052 (Rubber and Plastics Hose and Belting), asthma, peak flow testing, isocyanates, Radioallergosorbent tests (RAST), ELISA testing, TDI, PPI

Abstract: NIOSH conducted this HHE to investigate respiratory complaints (including asthma) at a plastics manufacturer.

Investigators conducted a respiratory symptom questionnaire, which was completed by $72 \%$ of hourly workers and revealed a high prevalence of respiratory symptoms. Environmental sampling was performed to assess possible exposures to respiratory irritants or asthma-producing compounds. The IH survey found trace amounts of airborne TDI during urethane extrusion and 12 inches from a locally ventilated glue pot.

In addition, quantifiable amounts of PPI were identified in the same two areas, as well as 12 inches from a glue pot without local ventilation. Subsequent medical evaluations attempted to determine the 
prevalence of occupational asthma and to assess the potential relationship between cases of asthma and exposure to either TDI or PPI. Peak flow testing was abnormal in $23 \%$ of those tested, and markers of immunologic response to PPI and TDI were positive in $14 \%$ to $45 \%$. Although the immunologic responses did not prove that the symptoms were related to these chemicals, they do indicate that exposure has occurred and in some individuals may be the cause of the symptoms. The standard isocyanate recommendations were provided.

\section{HETA 89-318-2273 November 1992}

Requester: Union

Method(s): OSHA 47

Range of isocyanates: ND because of analytical limitations (LODs of 185 and $1230 \mu \mathrm{g} / \mathrm{m}^{3}$, respectively, for MDI and MDI polyisocyanate)

Purpose: To evaluate possible health effects and lack of adequate personal protection among workers exposed to MDI in encapsulation systems used to seal joints in underground gas mains Keywords: SIC 4932 (Gas and Other Services Combined), SIC 4931

(Electric and Other Services Combined), MDI, MDI polyisocyanate

Abstract: NIOSH received a request for an HHE to evaluate possible health effects and lack of adequate personal protection among workers exposed to MDI in encapsulation systems used to seal joints in underground gas mains. NIOSH investigators performed medical interviews and PBZ and $\mathrm{GA}$ air sampling at three application sites where a total of five joints were being sealed. Air sampling was conducted above and below road level for MDI and MDI polyisocyanate. One of these sites contained 12 inch mains and the other sites had 6 inch mains. At each application site, two GA air samples for MDI and MDI polyisocyanate were collected, one below road level and one above road level approximately 3 to 4 feet from the hole. No MDI or MDI polyisocyanate was detected in any of the air samples collected during the NIOSH survey. However, the minimum detectable concentrations of MDI polyisocyanate in the encapsulation systems were high due to sampling and analytical limitations (185 and $1,230 \mu \mathrm{g} / \mathrm{m}^{3}$, respectively). Therefore, workers who enter the holes may be exposed to hazardous levels of MDI polyisocyanate that were ND due to limitations in the method used in this survey. Exposure limits for MDI polyisocyanate have not been defined by OSHA or NIOSH. Twelve of 21 workers interviewed reported experiencing eye, nose, and throat irritation when they used the paint primer. Cramped work spaces, especially when repairing pipes below street level, made it difficult to avoid inhalation and dermal exposure to the chemicals. No worker interviewed could confirm that he had been fit tested or properly trained to wear respiratory protection. Observations made onsite indicated the workers had not been trained in the appropriate procedures for donning respiratory protective devices. In addition, the latex gloves provided by the manufacturers of the encapsulation systems were inadequate to protect workers from dermal exposure to the liquid chemicals in these systems. All of the standard isocyanate recommendations were provided.

\section{HETA 90-0174-2231 Jully 1992}

Requester: Management

Method(s): NA

Range of isocyanates: NA

Purpose: To investigate exposures associated with a powder-coating operation and evaluate the possibility that workers' long-term health problems may be linked to the isocyanates used in some of the powder coatings

Keywords: SIC 3479 (Coating, Engraving, and Allied Services, not elsewhere classified), powder coating, epoxy, polyester, aldehyde, caprolactam, isocyanate

Abstract: NIOSH conducted this HHE to investigate exposures associated with a powder-coating operation and evaluate the 
possibility that workers' long-term health problems may be linked to the isocyanates used in some of the powder coatings. Technical problems with isocyanate sampling and analytical methodology had made it impractical to sample for isocyanates in the work place, and therefore, investigators could not determine if workers were overexposed to isocyanates. Potentially hazardous exposures were documented to other compounds, but a questionnaire survey of current workers did not reveal any significant association between current exposures and current symptoms or diseases.

Recommendations were provided to reduce or control potential isocyanate and other hazardous exposures, and to improve the safety and health conditions in general.

\section{HETA 93-0436-2569 March 1996}

Requester: Employee

Method(s): NIOSH 5522 (when an interim method)

Range of isocyanates: ND to $81.8 \mu \mathrm{g} / \mathrm{m}^{3}$ MDI, ND to $181.4 \mu \mathrm{g} / \mathrm{m}^{3}$ MDI oligomer (10-minute sample), ND to $54.9 \mu \mathrm{g} / \mathrm{m}^{3}$ TRIG (10-minute sample)

Purpose: To evaluate the occurrence of occupational asthma, apparently related to isocyanate exposure

Keywords: SIC 2493 (Reconstituted Wood Products), oriented strand boards, MDI, NCO, MDA, aspen, wood dust, lumber, asthma, HP

Abstract: NIOSH investigators conducted an HHE at this parallel strand lumber plant to evaluate the occurrence of occupational asthma, apparently related to isocyanate exposure. The company manufactured lumber products using long strands of aspen wood bound together with a MDI resin, and ten workers at the facility had a physician's diagnosis of occupational asthma attributed to MDI exposure. NIOSH conducted an environmental and medical survey at the facility. The environmental survey consisted of area air sampling for MDI, TRIG, and MDA. During the medical survey, a health, symptoms, and occupational history questionnaire was administered to current workers. Two area air samples had monomeric MDI concentrations that exceeded the NIOSH REL and ACGIH TLV for personal exposure of $50 \mu \mathrm{g} / \mathrm{m}^{3}$. The samples were from an area that is primarily unoccupied but is used for access to the blenders. The samples also had TRIG concentrations that exceeded the UK control limit of $20 \mu \mathrm{g} / \mathrm{m}^{3}$. At least 18 workers had developed respiratory illness that met the NIOSH case definition for occupational asthma since the plant began production in October 1991. Although changes in ventilation took effect in 1993, 9 (50\%) of these 18 cases developed after this change, and 4 of these cases were in workers who began their employment after the ventilation changes were made. On the basis of the information collected during this evaluation, NIOSH investigators concluded that a health hazard existed from exposure to isocyanates at this facility. Investigators provided all the standard isocyanate recommendations.

\section{HETA 94-0134 April 1994}

Requester: Government

Method(s): NIOSH 5521, 5522

Range of isocyanates: ND (MDI monomer and oligomers)

Purpose: To provide assistance to a health department in measuring MDI at a manufacturer of window shades

Keywords: SIC 2591 (Drapery Hardware)

MDI, methylene diisocyanate

Abstract: NIOSH provided TA to a local health department to measure MDI concentrations at a manufacturer of window shades. Samples collected using NIOSH method 5521 were all below the LOD of $0.3 \mu \mathrm{g} /$ sample. Since methods 5521 and 5522 have similar LODs, the samples 
collected using method 5522 were not analyzed and assumed to be ND. NIOSH concluded, based on this sampling, that no measurable airborne MDI exposures existed at this facility.

\section{HETA 99-0039 April 1999}

Requester: Government

Method(s): NA

Range of isocyanates: NA

Purpose: To investigate a reported case

of work-related asthma related to exposure to isocyanates at a surgical supplies manufacturer

Keywords: SIC 3842 (Orthopedic, Prosthetic, and Surgical Appliances and Supplies), asthma, isocyanates, MDI, orthopedics, casts, surgical casting wraps

Abstract: NIOSH conducted an HHE to investigate a reported case of work-related asthma and resulting concerns that other workers were at risk of exposure and disease. The health department requested information about the following: chemicals in use; severity of inhalation exposures; the potential for dermal absorption; the adequacy of ventilation, engineering controls, and work practices used to limit exposure; the employer's hazard communication program; and employee training related to exposures and exposure controls. NIOSH collected information to answer these questions, and they found that the orthopedic casting wraps that the case and coworkers tested for product research and development contained MDI. The employer had extensive programs and controls in place to protect workers from exposure to isocyanates. However, the protective gloves provided by the employer were not protective against isocyanate exposure. NIOSH recommended that the employer choose the most appropriate type of glove to protect workers from skin exposure and use glove breakthrough indicators to detect glove penetration.

\section{REFERENGES}

1. NIOSH (1978). Criteria for a recommended standard: occupational exposure to diisocyanates. Cincinnati, OH: U.S. Department of Health, Education, and Welfare, Public Health Service, Center for Disease Control, National Institute for Occupational Safety and Health, DHEW (NIOSH) Publication No. 78-215.

2. NIOSH (1990). Pocket guide to chemical hazards. Cincinnati, OH: U.S. Department of Health and Human Services, Public Health Service, Centers for Disease Control, National Institute for Occupational Safety and Health, DHHS (NIOSH) Publication No. 90-117.

3. NIOSH (1986). Occupational respiratory diseases. Cincinnati, OH: U.S. Department of Health and Human Services, Public Health Service, Centers for Disease Control, National Institute for Occupational Safety and Health, DHHS (NIOSH) Publication No. 86-102.

4. Levy BS, Wegman DH, eds. (1988). Occupational health: recognizing and preventing work-related diseases. 2nd ed. Boston/Toronto: Little, Brown and Company.

5. Porter CV, Higgins RL, Scheel LD (1975). A retrospective study of clinical, physiologic, and immunologic changes in workers exposed to toluene diisocyanate. Am Ind Hyg Assoc $\mathrm{J}$ 36:159-168.

6. Chan Yeung M, Lam S (1986). Occupational asthma. Am Rev Respir Dis 133:686-703.

7. NIOSH (1981). Technical report: respiratory and immunologic evaluation of isocyanate exposure in a new manufacturing plant. Cincinnati, OH: U.S. Department of Health and Human Services, Public Health Service, 
Centers for Disease Control, National Institute for Occupational Safety and Health, DHHS (NIOSH) Publication No. 81-125.

8. McKay RT, Brooks SM (1981). Toluene diisocyanate (TDI): biochemical and physiologic studies. Am Rev Resp Dis 123:132.

9. Harries M, Burge S, Samson M, Taylor A, Pepys J (1979). Isocyanate asthma: respiratory symptoms due to 1,5-naphthylene di-isocyanate. Thorax 34:762-766.

10. Woolrich PF (1982). Toxicology, industrial hygiene and medical control of TDI, MDI, and PMPPI. Am Ind Hyg Assoc J 43:89-98.

11. Mobay Corporation (1983). Health \& safety information for MDI, diphenylmethane diisocyanate, monomeric, polymeric, modified. Pittsburgh, PA: Mobay Corporation.

12. Berlin L, Hjortsberg U, Wass U (1981). Life-threatening pulmonary reaction to car paint containing a prepolymerized isocyanate. Scand $J$ Work Environ Health 7:310-312.

13. Zammit-Tabona M, Sherkin M, Kijek K, Chan H, Chan-Yeung M (1983). Asthma caused by diphenylmethane diisocyanate in foundry workers. Am Rev Respir Dis 128:226-230.

14. Chang KC, Karol MH (1984). Diphenylmethane diisocyanate (MDI)induced asthma: evaluation of immunologic responses and application of an animal model of isocyanate sensitivity. Clin Allergy 14:329-339.

15. Seguin P, Allard A, Cartier A, Malo JL (1987). Prevalence of occupational asthma in spray painters exposed to several types of isocyanates, including polymethylene polyphenyl isocyanate. J Occup Med 29:340-344.
16. Nielsen J, Sungo C, Winroth G, Hallberg T, Skerfving S (1985). Systemic reactions associated with polyisocyanate exposure. Scand $J$ Work Environ Health 1 1:51-54.

17. Alexandersson $R$, Gustafsson $P$, Hedenstierna G, Rosen G (1986). Exposure to naphthalene-diisocyanate in a rubber plant: symptoms and lung function. Arch Environ Health $41: 85-89$.

18. Mapp CE, Chiesura-Corona $P$, DeMarzo N, Fabbri L (1988). Persistent asthma due to isocyanates. Am Rev Resp Dis 137:1326-1329.

19. Liss GM, Bernstein DI, Moller DR, Gallagher JS, Stephenson RL, Bernstein IL (1988). Pulmonary and immunologic evaluation of foundry workers exposed to methylene diphenyldiisocyanate (MDI). J Allergy Clin Immunol 82:55-61.

20. Keskinen H, Tupasela O, Tiikkainen U, Nordman H (1988). Experiences of specific IgE in asthma due to diisocyanates. Clinical Allergy 18:597-604.

21. Cartier A, Grammar L, Malo JL, Lagier F, Ghezzo H, Harris K, Patterson R (1989). Specific serum antibodies against isocyanates: association with occupational asthma. J Allergy Clin Immunol 84:507-514.

22. Mobay Corporation (1991). Hexamethylene diisocyanate based polyisocyanates, health and safety information. Pittsburgh, PA: Mobay Corporation.

23. Vandenplas $\mathrm{O}$, Cartier $\mathrm{A}$, Lesage $\mathrm{J}$, Perrault G, Grammar LC, Malo JL (1992). Occupational asthma caused by a prepolymer but not the monomer of toluene diisocyanate (TDI). J Allergy Clin Immunol 89:1 183-1 188. 
24. Vandenplas O, Cartier A, Lesage J, Cloutier Y, Perrault G, Grammar LC, Shaughnessy MA, Malo JL (1992). Prepolymers of hexamethylene diisocyanate as a cause of occupational asthma. J Allergy Clin Immunol $91: 850-861$.

25. Baur X, Marek W, Ammon J, Czuppon AB, Marczynski B, RaulfHeimsoth M, Roemmelt H, Fruhmann G (1994). Respiratory and other hazards of isocyanates. Int Arch Occup Environ Health 66:141-152.

26. Weill H (1979). Epidemiologic and medical legal aspects of occupational asthma. J Allergy Clin Immunol 64:662-664.

27. Adams WGF (1975). Long-term effects on the health of men engaged in the manufacture of tolylene diisocyanate. Brit J Ind Med 32:72-78.

28. White WG, Sugden E, Morris MJ, Zapata E (1980). Isocyanate-induced asthma in a car factory. Lancet $i: 756-760$.

29. Karol MH, Hauth BA, Riley EJ, Magreni CM (1981). Dermal contact with toluene diisocyanate (TDI) produces respiratory tract hypersensitivity in guinea pigs. Toxicol Appl Pharmacol 58:221-230.

30. Erjefalt I, Persson CGA (1992). Increased sensitivity to toluene diisocyanate (TDI) in airways previously exposed to low doses of TDI. Clin ExP Allergy 22:854-862.

31. Rattray NJ, Bothman PA, Hext PM, Woodcock DR, Fielding I, Dearman RJ, Kimber I (1994). Induction of respiratory hypersensitivity to diphenylmethane4,4'-diisocyanate (MDI) in guinea pigs. Influence of route of exposure. Toxicol 88:15-30.
32. Bickis U (1994). Investigation of dermally induced airway hyperreactivity to toluene diisocyanate in guinea pigs (Dissertation). Kingston, Ontario, Canada: Queens University, Department of Pharmacology and Toxicology.

33. Baur X, Dewair M, Rommelt H (1984). Acute airway obstruction followed by hypersensitivity pneumonitis in an isocyanate (MDI) worker. J Occup Med 26:285-287.

34. Yoshizawa Y, Ohtsuka M, Noguchi K, Uchida Y, Suko M, Hasegawa S (1989). Hypersensitivity pneumonitis induced by toluene diisocyanate: sequelae of continuous exposure. Ann Intern Med 110:31-34.

35. Selden AI, Belin L, Wass U (1989). Isocyanate exposure and hypersensitivity pneumonitis-report of a probable case and prevalence of specific immunoglobulin $\mathrm{G}$ antibodies among exposed individuals. Scand J Work Environ Health 15:234-237.

36. Vanderplas O, Malo JL, Dugas M, Cartier A, Desjardins A, Levesque J, Shaughnessy MA, Grammar LC (1993). Hypersensitivity pneumonitislike reaction among workers exposed to diphenylmethane diisocyanate (MDI). Am Rev Res Dis 47:338-346.

37. NIOSH (1992). Recommendations for occupational safety and health, compendium of policy documents and statements. Cincinnati, $\mathrm{OH}$ : U.S. Department of Health and Human Services, Public Health Service, Centers for Disease Control, National Institute for Occupational Safety and Health, DHHS (NIOSH) Publication No. 92-100. 
38. ACGIH (1996). 1996 threshold limit values for chemical substances and physical agents and biological exposure indices. Cincinnati, $\mathrm{OH}$ : American Conference of Governmental Industrial Hygienists.

39. CFR. Code of Federal regulations (1989). Washington, DC: U.S. Government Printing Office.

40. Silk SJ, Hardy HL (1983). Control limits for isocyanates. Ann Occup Hyg 27:333-339.

41. Janko M, McCarthy K, Fajer M, van Raalte J (1992). Occupational exposure to 1,6-hexamethylene diisocyanate-based polyisocyanates in the State of Oregon, 1980-1990. Am Ind Hyg Assoc J 53:331-338.

42. NIOSH (1994). Determination of airborne isocyanate exposure. Chapter K. NIOSH manual of analytical methods, 4th ed. Cincinnati, OH: U.S.
Department of Health and Human Services, Public Health Service, Centers for Disease Control and Prevention, National Institute for Occupational Safety and Health, DHHS (NIOSH) Publication No. 94-1 13.

43. NIOSH (1994). Method 5525, Isocyanates, total (MAP) Issue 1, (Supplement in press). NIOSH methods of analytical methods, 4th ed. Cincinnati, Ohio: U.S. Department of Health and Human Services, Centers for Disease Control and Prevention, National Institute for Occupational Safety and Health, DHHS (NIOSH) Publication No. 94-1 13.

44. Bello D, Streicher RP, Woskie SR (2002). Evaluation of the NIOSH draft method 5525 for determination of the total reactive isocyanage group (Trig) for Aliphatic Isocyanates in auto body repair shops. J Environ Med 4:351-360. 